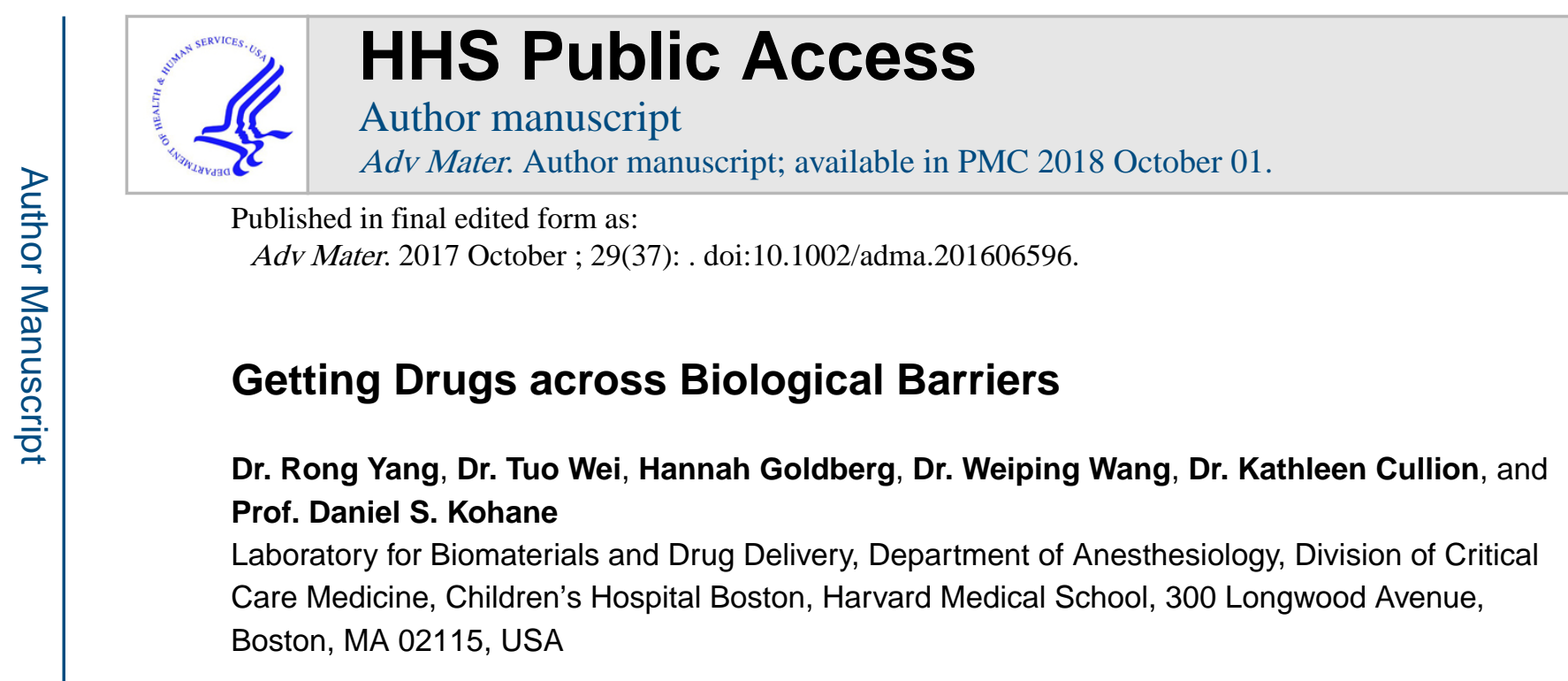

Abstract

The delivery of drugs to a target site frequently involves crossing biological barriers. The degree and nature of the impediment to flux, as well as the potential approaches to overcoming it, depend on the tissue, the drug, and numerous other factors. Here we present an overview of approaches that have been taken to crossing biological barriers, with special attention to transdermal drug delivery. Technology and knowledge pertaining to addressing these issues in a variety of organs could have a significant clinical impact.

\title{
The table of contents
}

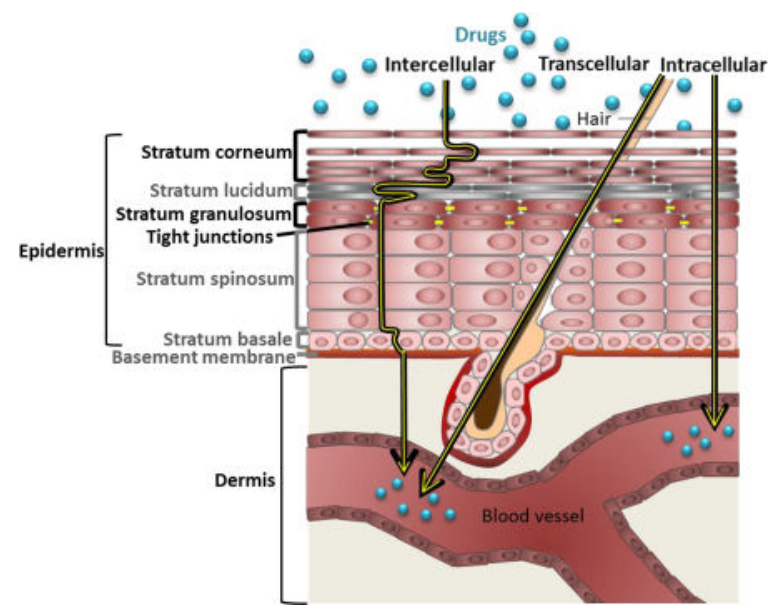

Biological barriers throughout the body present challenges for drug delivery. Chemical, physical, and biomolecule-mediated approaches to overcoming biological barriers have been developed for a variety of anatomic locations. The mechanisms and applications of these approaches are reviewed in this paper.

\section{Keywords}

drug delivery; biological barriers; transdermal transport 


\section{Introduction}

Drug delivery systems have been developed to address a wide range of problems in pharmacokinetics. Often, those entail the drug crossing one or more biological barriers that exist throughout the body - tissues and/or materials produced by tissues - which block the exchange of matter. These barriers may be obvious physical entities, such as skin, or more poorly defined, such as the connective tissue around a nerve and/or the various sheaths that surround it (per-, epi-, and endoneurium), and/or the lipid-rich Schwann cells prominent around some axon types. Barriers may not initially be recognized as being obstacles or as being addressable by drug delivery systems. Barriers may be substantially free of living cells, like the outer layer of skin, or may be composed of cells with connections that make circumventing them difficult, as in the blood-brain barrier. The types of mechanisms that are potentially available for crossing barriers are therefore very different from tissue to tissue; penetration of some obstacles, where cells are not the primary impediment, are likely amenable to manipulation by relatively straightforward physicochemical principles, while cellular obstacles can entail receptor-mediated phenomena etc. Barriers may be water-rich (cornea), or -poor (skin); thick or thin; local fluid turnover may be relatively static or nonexistent (skin) or a major factor (the cornea); the nature and degree of local vascularization can be very variable. There may be additional factors preventing drug flux, such as destruction of the drug before it has the chance to cross (e.g. proteolysis in the gut), or ejection of the drug from the body after uptake by endogenous transport (efflux) systems. There may be more than one barrier type in effect to transport across a barrier, and more than one mechanism available to overcome them.

From the above, it is apparent that there are many potential parameters that can be important in designing drug delivery systems to overcome specific barriers. The purpose of these systems is to enable a drug to cross a barrier that it could not otherwise cross by reasonable means at safe doses; their effect is therefore pharmacokinetic. The pharmacological effect per se of the drug - i.e. its pharmacodynamic profile - should be unchanged. (There are cases where the use of a drug delivery system may change what the drug appears to do. For example, quaternary lidocaine derivatives produce both motor and sensory nerve blockade, but chemical permeation enhancers [CPEs] can make them relatively senory-selective. ${ }^{[1]} \mathrm{We}$ have speculated that this effect, which we termed "pseudopharmacodynamic", was not due to a change in the intrinsic effect of the drugs, but due to distribution toward myelinated motor neurons and away from sensory ones under the influence of CPEs.) In some cases, the ability to cross a barrier, such as skin, can reproduce the effect that the drug might have when taken by a more conventional route, such as oral delivery. In such cases, the clinical value will lie in some other potential attribute, such as convenience, avoidance of first-pass hepatic metabolism (metabolism occurring when drug is taken up from the gastrointestinal (GI) tract and delivered to the liver by portal blood flow), achievement of constant therapeutic blood levels over extended periods, etc.

Perhaps the most obvious and important characteristic of the target site that affects design of the drug delivery system is ease of access. One can, for example, readily place a drug delivery system on the skin, and perhaps maintain it there with an occlusive dressing or in a patch (a drug delivery device that adheres to the skin). Application is not as simple in 
locations deep inside the body. Moreover, for reasons alluded to above, the precise nature of the problem to be overcome, and therefore the design characteristics of appropriate drug delivery systems, depend in large part on the specific barrier, and the associated organ systems. A review in depth of all the potential mechanisms in all anatomical locations cannot be easily contained in one review article. Here we will provide an overview of the major types of situations where drug delivery systems have been devised to cross biological barriers (Figure 1). Transdermal drug delivery will receive special emphasis as it is the best studied and understood, and has had by far the greatest penetration into clinical practice. Delivery approaches across other barriers often derive from lessons learned from skin (e.g., CPEs to enhance drug penetration to nerve, ${ }^{[2]}$ or across the tympanic membrane ${ }^{[3]}$ ), or may not (e.g., receptor-mediated delivery across the blood-brain barrier ${ }^{[4]}$ ). This review will cover barriers to drug delivery at the tissue/organ level; delivery into cells or cellular organelles has been reviewed elsewhere. ${ }^{[5-7]}$

This review will not be able to impart a perfect ability to predict what will work: the lessons learned in one context do not always translate into others, even when one might expect them to. For example, CPEs increase drug flux across skin, ${ }^{[8]}$ and the tympanic membrane, ${ }^{[3,9]}$ and dramatically enhance the local anesthetic effectiveness of tetrodotoxin in peripheral nerve. ${ }^{[2]}$ However, they do not have much effect on tetrodotoxin in topical corneal anesthesia. ${ }^{[10]}$ Such instances reflect the fact that our understanding of the processes in play remains incomplete.

On occasion, we refer to technologies that are commercially available or are under commercialization. We do so for purely illustrative purposes. Their mention is not an endorsement, nor is omission to be taken as a negative judgement on a technology. Moreover, we were limited by the reality that it is difficult to track down all compounds and methods that are in clinical trials, or to give an objective appreciation of their merits.

\section{Assessing Delivery across Biological Barriers}

Delivery of a range of molecules and even particles is now possible, at least experimentally, across a wide variety of barriers. There are a number of relatively standard or at least common metrics that are used to study their effectiveness. Comparing systems based on the literature remains difficult, due to the range of drugs studied (in type and quantity), specifics of the animal models used, metrics used for success, etc. Comparison becomes even more difficult when considering formulations undergoing commercialization, where key results may not be in the public domain. (Here as in all branches of research, the fact that negative results tend not to be published hinders a full understanding of the relevant science.)

In interpreting studies, it is important to bear in mind that the obvious reason for an observed effect by a given technology may not actually be reason it occurs. For example, a change in drug flux in an ultrasound-mediated drug delivery system may not just be due to the factors described in Section 3.3.2.2, but also due to a change in interstitial pressure leading to an alteration in the movement of interstitial fluids and solutes. ${ }^{[11]}$ 


\subsection{Benchtop Assessment of Flux}

For biological barriers that can be physically defined - such as skin - flux is often measured with a system analogous to a Franz diffusion cell: the test drug in a relevant formulation is placed in a donor chamber on one side of the barrier, and drug is collected in an appropriate fluid in the receptor chamber which is usually changed frequently to prevent diminution of the concentration gradient across the barrier. ${ }^{[12-13]}$ The "relevant" formulation is generally the one in which the drug will be applied. The selection of an "appropriate" receptor fluid is somewhat more difficult. It is rare for drugs to cross into a simple salt solution (they often cross into very cellular environments) and the composition of the receptor fluid (e.g. the presence of albumin) will affect drug solubility therein, the concentration of free drug, etc. Similar approaches can be used in in vitro systems such as Transwell@ plates, assuming and this is a big assumption - that the cell-based models of tissue permeability have been validated in a meaningful way; these have been reviewed elsewhere. ${ }^{[14-15]}$

Measurement of flux can be complicated when flux into the barrier itself is the goal, as in treatment of skin or nail diseases. In such situations, the drug may be difficult to extract uniformly from the tissue, and it is important to ensure that the entirety of the delivery device is removed prior to measurement (to avoid overestimating flux), or that drug is not eluted in efforts to remove it, e.g., by solvents (which would underestimate flux).

Such experiments generally also do not reflect other important ambient conditions on either side of the barrier. There is often bulk fluid flow outside the barrier, which can act to displace the drug and/or device, such as tears on the cornea or luminal flow of chyme in the gut. Mechanical events, such as blinking, peristalsis, or limb movement, can have similar effects. Fluid turnover on the side of the barrier inside the body is an almost ubiquitous phenomenon. There have been numerous efforts to model fluid turnover in vitro or in silico. ${ }^{[16-17]}$

Standard flux experiments may not be ideal if a prolonged duration of treatment is important, e.g. if the goal is to treat for a period of days. For example, in middle ear infections the current recommendation is to treat for 10 days. It may not be possible to maintain the barrier/tissue (in this case the tympanic membrane) ex vivo in a diffusion apparatus for several days due to decomposition and/or bacterial overgrowth. Demonstration of effectiveness over time therefore may depend on in vivo studies. Standard flux studies also usually do not speak to other crucial aspects of the design, such as whether formulations adhere well to the surface to which they are applied, etc.

The effects of the device on tissue may not be seen in in vitro/ex vivo experiments. For example, the device itself - or some component of it - may cause inflammation in vivo, which may affect flux across the barrier (Sec. 3.1), or may adversely affect the device's biocompatibility in that location; ${ }^{[18]}$ this would not be picked up ex vivo, where there is usually no inflammatory response. Furthermore, the therapeutic effect of the drug itself may affect drug flux, which might not be reflected in vitro. For example, delivery of an antibiotic or an anti-inflammatory drug to a disease affecting the barrier itself (e.g., infection of skin, tympanic membrane, cornea, etc.) may reduce the permeability of that barrier to the drug by successfully treating the condition. 
Consequently, the data obtained in in vitro/ex vivo experiments may not reflect what will actually happen in vivo, but an idealized flux under specific conditions where drug concentration downstream does not limit flux. (For those familiar with the assessment of other drug delivery systems, this is analogous to "infinite sink" studies. ${ }^{[19]}$ ) Nonetheless, such studies can be very useful for studying the effects on flux of differences between formulations or iterations of a given formulation.

Assessing flux is even more difficult in situations where the anatomical location of the barrier, or even its cellular and chemical nature, is not well understood (e.g. peripheral nerve) and/or where it is not easy to isolate and study the barrier in vitro (e.g. peripheral nerve and blood brain barrier). In such cases one may have to forgo in vitro testing, or rely on in vitro systems that purport to mimic the tissue of interest if such exist.

The bottom line is that in vitro and ex vivo systems can show whether a device could work, not whether they will.

\subsection{In Vivo Studies}

Imperfect as they are, in vivo studies come as close as one can to approximating human outcomes experimentally short of doing human trials. Here again, it is important that the animal model be validated - which is not always the same thing as being widely accepted and performed in a setting where reproducibility of results has been demonstrated.

In vivo testing usually pursues two primary objectives: demonstrating flux, and demonstrating biological effect.

Demonstration of flux usually entails pharmacokinetics studies that vary depending on the target organ. Typical studies include drug content of the barrier (e.g. skin) over time, bioavailability (systemic blood levels) over time, and biodistribution (uptake of drugs into various organs). Study of metabolism and elimination may also be necessary, depending on the degree to which the fate of the drugs is known. In some cases, it may be necessary to do comparable studies for the drug delivery system, or components thereof. In many cases, semi-quantitative metrics, such as tracking of fluorescence, have been employed. These studies can be instructive whether the device is intended for local or systemic drug distribution. In the former case (e.g. local anesthetic delivery to the skin) the systemic pharmacokinetics may address safety more than therapeutic effect. In the latter, it addresses both. However, distribution of a fluorophore or other analyte into or across a tissue of interest does not necessarily predict that a specific drug will be able to do so to a degree sufficient to have a therapeutic effect.

Pharmacokinetic studies can provide reassurance that the resulting blood (or other tissue) levels are consistent with what would be therapeutic in humans. This may be all that can be done in cases where there is a large disparity between the concentrations that are required for therapeutic effect in the subject species and in humans, or if the drug does not have the desired effect in a given species. Such pharmacokinetic experiments can be useful if the pharmacokinetics in humans are similar, and the drug's therapeutic effect is predictable from blood (or tissue) concentration. (For example, the glaucoma drug latanoprost does not 
reliably lower intraocular pressure in rabbits, but drug levels in the anterior chamber may be useful in predicting effect in humans, since the rabbit eye is in many ways similar to the human and the concentrations required for effect in humans are known. ${ }^{[20]}$ ) Nonetheless, demonstrations of the actual effect of the drug are important confirmations of the effectiveness of the system.

In vivo studies are perhaps the best predictors of safety - both local and systemic. Approaches to studying biocompatibility have been reviewed extensively. ${ }^{[21-22]}$ It is important to be mindful that local toxicity (i.e. at the site of device placement) can be due to the presence of the drug in concentrations around the device that would never occur were that drug given by its usual route. Occasionally, toxicological findings from in vivo studies can be hard to interpret due to a lack of understanding of their significance. As examples, one might not know what to make of transient disruption of the BBB - or even of what to look for to establish that it is safe, or whether to worry about the presence of a given degree of inflammation in skin or other tissues over an extended period, or whether it is harmful to poke small holes in the gut.

In vivo studies should be designed with real-world application in mind. For example, if a 1 $\mathrm{cm} \times 2 \mathrm{~cm}$ patch is shown to be effective in a mouse, it might suggest that the device could work in humans, but a commensurate device in humans might be $20 \times 40 \mathrm{~cm}$. That is obviously impractical.

\section{Transdermal Drug Delivery}

Efforts in transdermal drug delivery date back to the topical application of substances, such as ointments, in antiquity. ${ }^{[23]}$ Transdermal drug delivery has become a common medical practice, with the marketing of patches delivering a variety of drugs. ${ }^{[24]}$ Transdermal drug delivery has many advantages compared to other delivery routes. It is non-invasive, yet unlike oral delivery - avoids first-pass hepatic metabolism. It can be easy-to-use, as in a patch, and can provide continuous drug administration, both of which can enhance compliance. Treatment can be discontinued easily - simply by removing a topical device although there is likely to be a lag period between device removal and termination of effect. (Similarly, there often is a lag between device application and initiation of effect.) In some cases, such as in skin disorders, transdermal delivery provides direct access to the diseased site with reduced systemic toxicity. ${ }^{[25-26]}$ Skin is the most commonly studied biological barrier and its structure is similar to some of others (such as the tympanic membrane).

Transdermal drug delivery can be intended to deliver drugs locally, i.e. to the skin itself. For example, local anesthetics (e.g., lidocaine and prilocaine) can be delivered in a cream to numb the skin. ${ }^{[27]}$ More commonly, however, transdermal drug delivery is used to achieve noninvasive systemic drug distribution. For example, many transdermal formulations can deliver drugs affecting the central nervous system (CNS). ${ }^{[28]}$

\subsection{Skin Structure and Drug Penetration}

Skin is composed of the outer epidermis and the inner subjacent dermis (Figure 2a). The outermost layer of the epidermis is the 10-20- $\mu$ m-thick stratum corneum (SC), consisting of 
densely packed and highly keratinized dead cells. ${ }^{[29]}$ The SC represents the primary barrier to drug permeation. The remainder of the 50-120 $\mu \mathrm{m}$-thick epidermis is an avascular stratified squamous epithelium.

The SC can be described by a "brick and mortar" model (Figure 2b), where the bricks represent dead corneocytes (primarily composed of cross-linked keratin), and the mortar represents the lipids (composed mainly of cholesterol, free fatty acids, and ceramides) organized in lamellar crystalline bilayers (Figure 2c), which fill the intercellular spaces. ${ }^{[30]}$ Permeation can occur through the lipid bilayers (intercellular path), across the corneocytes (intracellular), or through hair follicles or sebaceous and/or sweat glands (transcellular). ${ }^{[31]}$

Most small molecules - drugs or CPEs - primarily traverse the SC via the intercellular path, which winds around corneocytes (Figure 2a). ${ }^{[32]}$ Due to the lipid-rich nature of the SC, successful transdermal drugs are typically relatively lipophilic (see Section 3.2).

There are four layers between the SC and dermis (i.e., the stratum lucidum, the stratum granulosum, the stratum spinosum, and the basal cell layer, Figure 2a). In the stratum granulosum, cells are connected by tight junctions which present a secondary barrier to drug permeation. In some diseases, such as atopic dermatitis, where the SC is disrupted, these tight junctions can become the major barrier to drug permeation. ${ }^{[33]}$

The epidermis is separated by a basement membrane from the dermis, a 1-2 mm thick connective tissue containing a rich capillary bed. In general, the challenge in transdermal delivery is in getting drugs across the epidermis - particularly the SC - to the dermal capillaries from where they will achieve systemic distribution.

In the following sections, we will first discuss therapeutics that can cross the skin with no enhancement, then the various enhancement mechanisms (i.e., chemical, physical, and biological).

\subsection{Drugs that Can Penetrate Skin}

Most of the transdermal patches in clinical use today deliver drugs that have some capacity to penetrate skin on their own. ${ }^{[32]}$ The development of such delivery systems surged in 2001, but tapered off since 2009 (Figure 3), reportedly because most of the drugs with suitable properties had been used (Figure 3). ${ }^{[28,32]}$ Such drugs predominantly penetrate the SC through the lipid bilayers. Although our understanding of the factors on the molecular level that affect skin permeation remains imperfect, it seems that favorable drug attributes include low molecular weight (MW) and a $\log P$ (i.e. the logarithm of the octanol-water partition coefficient of a molecule) between 0 and $5^{[34]} ; \log P$ s of about 2 are considered most suitable. ${ }^{[28]}$ It has been hypothesized that such molecules can cross both the hydrophilic head layer and the lipophilic tail layer of the lipid bilayers (Figure 2c) without being trapped. Theory notwithstanding, some molecules with relatively high molecular weight and high $\log P$ can cross skin to some extent. Even small fluxes of such compounds can be clinically effective if they are of high potency. ${ }^{[35]}$

Opioids have been among the drugs most commonly delivered by the transdermal route. ${ }^{[34]}$ One of the most successful examples is fentanyl (MW $=336.5 \mathrm{Da}, \log P=4.05) .{ }^{[36]}$ Fentanyl 
is a very potent opioid analgesic with a relatively short plasma half-life. ${ }^{[37]}$ The transdermal patch allows the steady dosing of fentanyl (at serum fentanyl concentrations of $0.3-2 \mathrm{ng}$ $\mathrm{mL}^{-1}$ ) over a 72-hour period from a single application. ${ }^{[38]}$ Such prolonged release extends the in-patient acute use of fentanyl to the out-patient setting for chronic pain. The broadening of the primary indication is thought to have led to its commercial success. Patches containing sufentanil ( $\mathrm{MW}=386.5 \mathrm{Da}, \log P=3.45$ ), a more potent derivative of fentanyl, have been in clinical trials. ${ }^{[39-40]}$

\subsection{Permeation Enhancement}

The library of drugs that can be delivered transdermally has been extended by various methods of enhancing skin permeability. The delivery of hydrophilic drugs and macromolecules has proven challenging, if at all possible, using chemical permeation enhancement methods (Section 3.3.1). ${ }^{[41]}$ Some physical permeation enhancement approaches (Section 3.3.2) can bring macromolecules, such as peptides, ${ }^{[42-43]}$ DNA, ${ }^{[43-44]}$ or small-interfering RNA, ${ }^{[44]}$ across skin via the transcellular or intercellular route. Biomolecule-mediated enhancement (Section 3.3.3) has shown promise in delivering biomacromolecules as well. ${ }^{[45]}$

3.3.1. Chemical Permeation Enhancement-CPEs are molecules that can penetrate skin and decrease the barrier effect reversibly. Numerous compounds have been screened for penetration enhancing activity, yet their inclusion in clinical transdermal formulations is limited (Table 1) ${ }^{[46]}$ Their underlying mechanisms of action are seldom clearly defined.

\subsubsection{Small molecule CPEs}

Theories of Transport and Enhancement: Quantitative characterization of transdermal transport kinetics has shed light on the underlying mechanisms, especially for small molecules given their well-defined physicochemical properties. The rate of the transdermal transport is limited by diffusion across the SC, which can be described by Fick's second law (Equation 1):

$$
\frac{\delta C}{\delta t}=D\left[\frac{\delta^{2} C}{\delta x^{2}}\right]_{\text {for } 0<x<h \text { and } 0<t<\infty}
$$

where $C$ is the concentration of the small molecule; $x$ is the distance from the surface of the $\mathrm{SC}$ to a given point in the skin measured normal to the SC; $D$ is the diffusion coefficient, $t$ is time, and $h$ is the thickness of the SC.

Real-world transdermal transport processes (e.g., when a patch is applied onto the skin of a patient) are usually transient (i.e., concentrations in the patch and skin change over time) at the beginning and the end of the transdermal application. The concentration profile of therapeutics inside skin during a transient process can be described by solving Equation (1) using the method of separation of variables and L'Hopital's Rule (Equation 2): ${ }^{[47]}$ 


$$
C(x, t)=\sum_{k=1}^{\infty} \frac{2 A}{h} \operatorname{Cos}\left(x \sqrt{\mu_{k}}\right) e^{\left(-\mathrm{Dt} \mu_{k}\right)}
$$

where $\mu_{k}=(2 k-1)^{2}\left[\frac{\pi}{2 h}\right]^{2}$, the constant of integration generated by separation of variables, $\pi=3.142$, and $A$ is the total mass of the molecule administered.

Equation (2) can be integrated from $x=0$ to $x=h$ at equally spaced time points from time zero to $t$ to give rise to the release profile over time (Equation 3 ):

$$
b=\int_{0}^{t} \int_{x=0}^{x=h} C(x, t) \mathrm{dxdt}=\int_{0}^{t} \int_{x=0}^{x=h} \sum_{k=1}^{\infty} \frac{2 A}{h} \operatorname{Cos}\left(x \sqrt{\mu_{k}}\right) e^{\left(-\mathrm{Dt} \mu_{k}\right)} \mathrm{dxdt}
$$

where $b$ is the cumulative mass of permeant that passes per unit area across the SC within time $t$.

The initial transient transport can last for 3-9 hours after the application of a transdermal formulation. ${ }^{[48]}$ If this transient period does not result in a significant change in concentration of the drug within the formulation (drug reservoir), i.e. it is a "pseudo-steady state process", Fick's first law applies and can be simplified to (Equation 4):

$$
\frac{\mathrm{db}}{\mathrm{dt}}=\frac{\mathrm{DC}_{0}}{h}
$$

where $C_{O}$ is the concentration of diffusant in the first layer of SC at the skin surface contacting the source of the penetrant. $C_{O}$ is difficult to measure experimentally, but can be calculated from $C_{O}$, the concentration of diffusant in the topical formulation/patch (Equation 5):

$$
C_{0}=\mathrm{PC}_{0}^{\prime}
$$

where $P$ is the partition coefficient of the diffusant between the formulation and the SC. Combining Equation (4) and Equation (5), one can see that the rate of transdermal delivery $(d b / d t)$ is governed by the partition of the molecules (drug or CPE) into the SC, and the diffusion coefficient of the molecules in the SC.

Molecular transport theories attribute permeation enhancement by CPEs to their physicochemical properties, described by the solubility parameters: hydrogen bonding $\left(\delta_{h}\right)$, polar interactions (i.e., dipole-dipole interactions; $\delta_{p}$ ), and dispersive interactions (i.e., temporarily induced dipole interactions; $\left.\delta_{d}\right) .{ }^{[49]}$ The cohesive energy density $E_{c}$ (i.e., the 
amount of energy needed to completely remove unit volume of molecules from their neighbors to infinite separation) can be calculated as follows (Equation 6):

$$
E_{c}=\delta_{h}^{2}+\delta_{p}^{2}+\delta_{d}^{2}
$$

Small molecule CPEs can be categorized as ones that partition into SC lipids ("fluidizers", which increase both the partition and the diffusion coefficients by changing the properties of the SC), and ones that extract lipids from the SC ("extractors", which increase the diffusion coefficient by creating pores). Most fluidizers are lipophilic. Their partition into the lipid bilayers, and thus ability to enhance permeation, is determined by the lipophilicity, quantified by $\log P$. Some of the fluidizers (such as solvents [see Section 3.3.1.1a] and azone [see Section 3.3.1.1e]) can form a separate phase inside the SC, acting as drug reservoirs for sustained permeation enhancement; others (such as fatty acids [see Section 3.3.1.1b] and terpenes [see Section 3.3.1.1d]) can insert themselves into the SC lipid bilayer and form a pathway for drugs to go across the SC.$^{[8,50-53]}$ For extractors, hydrogen bonding is the main known mechanism of extraction of lipids from the SC. The interaction between extractors and lipids competes with the water-mediated intermolecular hydrogen bonding between lipids inside the SC. ${ }^{[8]}$ Therefore, a molecule's usefulness as an extractor correlates with the ratio of $\delta_{h}$ to the square root of their cohesive energy density $E_{c}$.

There are other enhancement mechanisms, such as altering the protein structure of keratin in corneocytes. Such CPEs tend to have greater irritation potential and are less commonly used in transdermal formulations. ${ }^{[49]}$

Case studies of common CPEs' enhancement mechanisms: In this section, we discuss the specific molecular interactions between common potent permeation enhancers and the lipid bilayers in the SC. The molecular structures of all of the molecules mentioned below can be found in Table 2.

a. Solvents: Solvents are small organic molecules which are liquid at room temperature, usually inexpensive, and commonly use to dissolve substances. Commonly used solvent CPEs include ethanol, pyrrolidones, and sulfoxides (Table 2). Ethanol is used in many transdermal formulations and patches, such as the ones for estradiol and nitroglycerin. It partitions into and permeates the SC with a steady state flux of $\sim 1 \mathrm{mg} \mathrm{cm}^{-1} \mathrm{~h}^{-1}{ }^{\left[{ }^{[54]}\right.}$ Ethanol is a hydrophilic fluidizer $(\log P=-0.3)$. It dissolves into and alters the solubility properties of the SC, and increases the partition coefficients of drugs. ${ }^{[8]}$

At low concentrations, pyrrolidones $(\log P \sim-0.6-0.5)$ partition into and alter the solubility properties of the SC. At higher concentrations, pyrrolidones can generate their own phase inside the SC, which can serve as a reservoir for drugs and thus enable sustained release. ${ }^{[8]}$ Sodium pyrrolidone carboxylate has been approved by the US FDA for topical application (Tables 1 and 2). Dimethyl sulfoxide (DMSO) and decyl methyl sulfoxide are also US FDAapproved (Tables 1 and 2). Sulfoxides can change the intercellular keratin confirmation, ${ }^{[55-56]}$ possibly interact with the hydrophilic head groups of lipids and distort their bilayers, changing the solubility properties of the SC. ${ }^{[8]}$ 
b. Fatty acids: Fatty acids refer to carboxylic acids with long aliphatic chains, which can be saturated or unsaturated (Table 2). Fatty acids have long been used in transdermal delivery. The most commonly used long-chain fatty acid CPE, oleic acid ( $\log P=7.7$, Table 2$)$ has been approved by the US FDA for topical application at concentrations up to $25 \% \mathrm{w} / \mathrm{w}$ (Table 1). A saturated chain with $10-12$ carbon atoms or an unsaturated chain with 18 carbon atoms and cis configuration appears to yield the most potent enhancers. ${ }^{[57-58]}$ For unsaturated chains, the cis configuration can achieve greater permeation enhancement than the trans configuration, likely because of greater disturbance of intercellular lipid packing from the bent structure. ${ }^{[8]}$ Spectroscopic investigations and electron microscopic studies revealed that oleic acid can insert itself into lipid bilayers, providing permeation pathways for therapeutics. ${ }^{[51-52]}$

c. Surfactants: Surfactants are amphiphilic organic compounds, meaning they contain both lipophilic and hydrophilic groups. Surfactants are found in many therapeutic and cosmetic preparations. The anionic sodium lauryl sulfate (SLS, Table 2) is commonly used and has been US FDA-approved for topical application at concentrations up to $40 \% \mathrm{w} / \mathrm{v}$ (Table 1). SLS and similar anionic surfactants (such as SLS, sodium octyl sulfate, and sodium laureth sulfate) tend to penetrate the SC poorly within the first few hours of contact, and consequently have relatively little effect on drug permeation in that time frame. They do increase drug permeation thereafter, possibly because of dissolution of the bilayer lipids and their known interaction with intercellular keratin. ${ }^{[59]}$ Non-ionic surfactants are considered less toxic than their anionic and cationic counterparts. ${ }^{[8]}$ Nonoxynol-9, a non-ionic surfactant approved by the US FDA at $0.01 \% \mathrm{w} / \mathrm{v}$ (Table 1 and 2), can traverse human skin slowly (at the rate of $\sim 1 \mu \mathrm{g} \mathrm{cm}^{-2} \mathrm{~h}^{-1}$ ). ${ }^{[60]}$

d. Terpenes: Terpenes are compounds with the molecular formula of $\left(\mathrm{C}_{5} \mathrm{H}_{8}\right)_{n}$ and consisting of isoprene linked together in linear chains or rings. They are commonly produced by plants and have long been used as medicines, spices, and fragrances in essential oils (i.e. concentrated hydrophobic liquids containing volatile aroma compounds), albeit with little government regulation. ${ }^{[61]}$

Lower molecular weight terpenes enhance drug permeation to a greater degree than larger ones. In addition, terpenes with polar groups promote the permeation of hydrophilic drugs and non-polar groups promote the permeation of lipophilic drugs. ${ }^{[8]}$ The observation that terpenes modify the solubility characteristics and partition coefficients within the SC implies that they are fluidizers, which was confirmed by small angle X-ray diffraction and steadystate diffusion experiments. ${ }^{[53]}$ Spectroscopic evidence suggested that terpenes can also insert themselves into the $\mathrm{SC}$, acting as a diffusion pathways for drugs. ${ }^{[53]}$

e. Azone: Azone ( $\log P=6.3$, Table 2$)$ was specifically designed as a skin penetration enhancer ${ }^{[62]}$ Azone has been tested in several clinical trials, applied topically over a wide range of concentrations and applied over extended periods (weeks). ${ }^{[63]}$ It is not approved by the US FDA, perhaps because it is an insecticide, fungicide, herbicide, and a plant growth regulator, and has antiviral activity (which may make it hard to argue that it is an inactive excipient). ${ }^{[64]}$ Its mechanism of permeation enhancement is not clearly understood. Azone 
likely acts as a fluidizer, as electron diffraction studies have shown that it can form a distinct phase within bilayer lipids. ${ }^{[50]}$

Some small-molecule CPEs can cause local "irritation". The definition of "irritation" is variable and hard to compare across different studies, and often bears only a vague relation to the intuitive or common medical use of the term. Irritation has been defined based on in vitro cytotoxicity, ${ }^{[49]}$ or in vivo reactions such as inflammation and necrosis. ${ }^{[3]}$ The balance between effectiveness and irritation - however defined - is an important consideration when choosing small molecule CPEs. Indices derived from the physicochemical properties of a particular CPE (such as the cohesive energy density $E_{c}$ and dipole-dipole interactions $\delta_{p}$, see above) have been proposed as potential predictors of effectiveness and irritation. ${ }^{\text {[49] }}$

Discrepancies between in vitro and in vivo assessments of tissue reaction are not uncommon $^{[21]}$ (see Section 2).

One way to potentially enhance effectiveness without increasing irritation is to use a combination of small-molecule CPEs, where the overall enhancement of flux by two (or more) CPEs is greater than the additive total of their individual effects. ${ }^{[65]}$ Thus, less CPE is required to achieve the same level of permeation enhancement, potentially reducing tissue toxicity.

A number of CPEs in the categories of solvents, fatty acids, terpenes, and surfactants have been approved by the FDA for topical use (Table 1), while azones remain to be approved.

3.3.1.2. Macromolecule-based chemical permeation enhancement: The transdermal delivery of hydrophilic and/or macromolecular therapeutics is an ongoing challenge. Recently several macromolecules have been discovered to enhance drug permeation, including hyaluronic acid (also called hyaluronan, HA), dendrimers, cyclodextrin, and chitosan (Figure 4).

Hyaluronic acid: HA is a linear polysaccharide (Figure 4A) naturally produced by humans ${ }^{[66]}$ and found abundantly in the extracellular matrix. ${ }^{[67]}$ It has been used in transdermal drug delivery because of its biocompatibility, biodegradability, nonimmunogenicity, and low toxicity. ${ }^{[67-68]}$ It was not until recently that HA was found to enhance the permeation of small drug molecules, ${ }^{[67]}$ such as diclofenac, ibuprofen, clindamycin phosphate and cyclosporine. HA has been approved by the US FDA for cosmetic use at $2.5 \% \mathrm{w} / \mathrm{w} .{ }^{[46]}$

HA has also been used to chemically modify macromolecules and the surface of nanoparticles to enhance their transdermal permeation. For example, the conjugate of HA and human growth hormone $(\mathrm{hGH})$ achieved greater permeation through mouse skin than did free hGH. ${ }^{[69]}$ Conjugating HA to nanographene oxide or carbon dot-chlorin e6 particles enhanced their permeation and/or retention in skin. ${ }^{[70-71]}$ Transdermal immunotherapy has been enabled by conjugating HA with antigenic peptides such as myostatin fragment ${ }^{[72]}$ or ovalbumin. ${ }^{[73]} \mathrm{HA}$ can enhance the permeation of macromolecules to a greater degree than some small-molecule CPEs, ${ }^{[74]}$ but not as much as some combinations of small-molecule CPEs. ${ }^{[42]}$ 
Several hypotheses exist to explain the mechanism of skin penetration by HA. ${ }^{[67-68,75]}$ First, a very high fraction of surrounding water molecules interacts strongly with the polymer backbone of HA via hydrogen bonding. HA formulations can thus promote the hydration of SC and loosen up the lipid bilayers for greater permeability of hydrophilic drugs. Second, the lipophilic domains in HA can interact with SC: contact with HA can cause keratin in the $\mathrm{SC}$ to change from an $a$-helical structure to a $\beta$-sheet and the lipid bilayers to become disordered. ${ }^{[75]}$ It is also possible that HA receptors expressed on living skin cells (e.g., keratinocytes and fibroblasts) may be involved in the active transport of HA and conjugated therapeutics. ${ }^{[69]}$

Dendrimers: Dendrimers are synthetic hyperbranched polymers (Figure 4B). Their core and highly functionalized branches can encapsulate hydrophilic and lipophilic drugs via hostguest interactions or chemical conjugation, giving rise to a versatile platform with high drug loading and high monodispersity.

Polyamidoamine (PAMAM) dendrimers have frequently been studied as CPEs. They have been used in the transdermal delivery of a variety of small molecule therapeutics including tamsulosin hydrochloride (a selective $a_{1 A^{-}}$adrenoceptor antagonist for urinary retention ${ }^{[76]}$ ), ketoprofen and diflunisal ${ }^{[77]}, 8$-methoxypsoralene ${ }^{[78]}$, riboflavin ${ }^{[79]}, 5$-fluorouracil, ${ }^{[80]}$ and indomethacin ${ }^{[81]}$ across rat or pig skin. Among them, indomethacin, a non-steroidal antiinflammatory drug, has the greatest $\log P(4.3)$ and minimal permeation across skin.

PAMAM dendrimers improved the transdermal delivery rate of indomethacin by a factor of 2-5 in vivo in rats, which resulted in reduced carrageenan-induced edema in the paws of rats by $25-55 \%$. ${ }^{[81]}$ PAMAM dendrimers can deliver genetic material transdermally. A transdermal delivery patch for plasmid pCF1CAT, where pCF1CAT (negatively charged due to the phosphate groups) was bound to PAMAM (positively charged due to the amine groups) via electrostatic interactions, enhanced the expression of transgenic chloramphenicol acetyl transferase in nude mice. ${ }^{[82]}$

Dendrimers can act by different mechanisms depending on their size (determined by the number of branch generations) and charge. Small dendrimers with one or two generations have high diffusion coefficients in the SC. ${ }^{[83]}$ They can act as fluidizers by quickly diffusing through the $\mathrm{SC}^{[84]}$ and changing the solubility, polarity, and structural integrity of the lipid bilayers. ${ }^{[83,85-86]}$ They have been reported to further improve the flux enhancement seen with small molecule CPEs such as isopropyl myristate. ${ }^{[80,83]}$ Although coarse-grained molecular dynamic simulation showed that larger dendrimers with generation numbers greater than four can penetrate biomembranes, ${ }^{[87]}$ this has not been borne out experimentally. ${ }^{[83-84,88]}$ Cationic dendrimers can disrupt the lipid bilayers by forming nanoscale pores. ${ }^{[89]}$ Dendrimers can also participate in transcellular penetration. For example fluorescein isothiocyanate (FITC)-labeled PAMAM dendrimers exhibited transcellular penetration (Figure 1) via hair follicles. ${ }^{[83,90]}$

Cyclodextrins: Cyclodextrins (CDs) are cyclic oligosaccharides with the repeat unit of a-Dglucopyranose connected via carbons at $a-1$ and $a-4 .^{[91-93]}$ CDs have a cone-like shape with hydrophilic hydroxyl groups on the outside of the cone and lipophilic skeletal carbons and ethereal oxygens on the surface of the internal cavity, where lipophilic guest molecules 
can be hosted (Figure 4C). The size of the cone can be tuned by including different numbers of glucopyranose units (typically between six and eight). ${ }^{[94-96]}$

Despite CDs' relatively low transdermal permeability resulting from their high MW and low $\log P(-3$ to 0.00$),{ }^{[97-98]}$ they can increase the skin penetration rate of lipophilic molecules with low solubility in the formulation. It is believed that CDs form complexes with drugs, increasing their solubility and stability, but CDs are not believed to increase the permeability of drugs across the SC. ${ }^{[99-101]}$ Transdermal transport of CD-drug complexes remains difficult. ${ }^{[102]}$ One approach to increasing the permeability to the complexes is to functionalize the surface of the "cone" with lipophilic moieties. Methylated $\beta$-CDs can act as extractors (Section 3.3.1.2) and increase the diffusion coefficients of the CD-drug complexes in SC lipid bilayers. ${ }^{[103-104]}$ Greater skin penetration can be achieved by combining CDs with small molecule CPEs. For example, the penetration of testosterone in mouse skin was accelerated when treated with both 2-hydroxyprolyl- $\beta$-CD and glycerol monoether. ${ }^{[105]}$

Chitosan and derivatives: Chitosans are a group of cationic polysaccharides composed of $\beta$ (1-4)-linked D-glucosamine and N-acetyl-D-glucosamine, randomly distributed along the backbone.

Skin penetration can be accomplished only by chitosans with low MW. Baicalin, an antitumor agent, has been delivered across mouse skin when mixed with low-MW chitosans. The maximum flux enhancement was achieved at a $\mathrm{pH}$ around 7.5, at which the amino groups in the chitosan were partially charged. Nuclear magnetic resonance (NMR) spectroscopy showed no electrostatic interaction of chitosans with keratin and glycoproteins in the SC, and the flux enhancement was therefore attributed to dipole-dipole and Van der Waals interactions with lipid bilayers. ${ }^{[106]}$ Chitosan derivatives, such as N-trimethyl chitosans ${ }^{[107-108]}$ and $\mathrm{N}$-arginine chitosans, ${ }^{[109]}$ have also been used as CPEs. Chitosan can also enhance trans-GI drug delivery (see Section 5.3).

Macromolecular CPEs can bring macromolecular therapeutics and nanoparticles across skin, which is very challenging for small-molecule CPEs. Small-molecule CPEs are generally more effective at delivering small-molecule drugs.

3.3.2. Permeation Enhancement by Physical Means-Methods such as lasers, ultrasound, iontophoresis and electroporation, microneedles, and magnetophoresis (Figure 5) have been used to deliver a range of therapeutics, including genetic materials and vaccines. ${ }^{[110-134]}$ In addition to the SC, physical permeation enhancement has been applied to the blood-brain barrier (BBB, see section 5.4) ${ }^{[135]}$ tumors (see Section 4.2), ${ }^{[113]}$ and the GI tract (see Section 5.3). ${ }^{[136]}$ Table 3 lists a selection of FDA-approved physical means for permeation enhancement.

3.3.2.1. Lasers: Laser can enhance the percutaneous permeation of drugs without extensive damage to the viable epidermis. ${ }^{[130]}$ Several laser-skin interactions occur that promote the transcutaneous flux of drugs, including direct ablation and generation of photomechanical waves. ${ }^{[130]}$ Direct ablation decomposes the SC by high energy (193 nm wavelength; 
irradiance from $70 \mathrm{~mJ} \mathrm{~cm}^{-2}$ to $500 \mathrm{~mJ} \mathrm{~cm}^{-2}$ per $14 \mathrm{~ns}$ pulse); ${ }^{[137]}$ it is considered a primary mechanism for laser-induced permeation enhancement. ${ }^{[129-130]}$ Photomechanical waves are unipolar compressional waves which occur during intense laser radiation. These waves are hundreds of atmospheres in magnitude and last nano- to micro-seconds. ${ }^{[129-130]}$ They may cause cell deformation and therefore permeabilization, but the detailed interactions are not well understood. ${ }^{[138]}$

The enhancement mechanisms also vary among the different types of light sources employed, including ultraviolet, infrared (such as erbium:yttrium-gallium-garnet [Er:YAG] lasers and $\mathrm{CO}_{2}$ laser), and ruby laser $(694 \mathrm{~nm}) \cdot{ }^{[130-132]}$ Microwave (2450 MHz [wavelength $12 \mathrm{~cm}$ ] for 10 minutes or $3985 \mathrm{MHz}$ [wavelength $7.5 \mathrm{~cm}$ ] for 5 minutes) has also been used to deliver 5-fluorouracil encapsulated in chitosan nanoparticles (with $\sim 100 \mathrm{~nm}$ diameter) across rat skin ex vivo. ${ }^{[139]} 2450 \mathrm{MHz}$ microwave increased skin permeation by the nanoparticles by nearly $100 \%$, and $3985 \mathrm{MHz}$ microwave by about $25 \%$.

Light from $\mathrm{CO}_{2}(10600 \mathrm{~nm})$ and Er:YAG lasers $(2940 \mathrm{~nm})$ can be absorbed by water molecules and induce photothermal effects, during which microchannel arrays are created in the SC due to the vaporization of water. ${ }^{[130]}$ However, the photothermal effect can cause skin irritation and/or thermal damage at the exposure site and adjacent tissues. Laserinduced permeation enhancement has been used to enhance the transport of prednisone and methotrexate into the dermis, to treat inflammation and psoriasis, respectively. ${ }^{[129,133]}$

3.3.2.2. Ultrasound: Ultrasound (US) is sound waves with frequencies above $20 \mathrm{kHz}$ (human hearing limit). US penetration depth is inversely proportional to the frequency. ${ }^{[140]}$

US-mediated permeation enhancement is achieved by cavitation: the formation, oscillation, and collapse of bubbles at the formulation/tissue interface or inside the tissue. ${ }^{[141-144]}$ Bubbles oscillating in size can lead to acoustic streaming (fluid flow parallel to the gas/ liquid interface) which exerts shear stress on the skin and enhances drug penetration. ${ }^{[143-146]}$ Bubbles collapsing at the skin surface result in localized shock waves that disrupt the SC and augment molecular transport for hours. ${ }^{[141,144,147]}$ The fate of bubbles can be controlled via US frequency, intensity, pulse duration, and the viscosity of the coupling medium. ${ }^{[144]}$

Simultaneous treatment with high- (>1 MHz) and low- $(20 \mathrm{kHz}$ to $100 \mathrm{kHz})$ frequency US (termed dual treatment) can enhance permeation to a greater degree than individual treatments at the same intensities. ${ }^{[148]}$ The boosted enhancement by dual treatment is attributed to the simultaneous generation (under high-frequency US) and collapse (under low-frequency US) of bubbles.

US has been used to enhance transport into numerous tissues and anatomic locations, including skin, ${ }^{[149]}$ tumor, ${ }^{[135]}$ the GI tract, ${ }^{[150]}$ cornea, ${ }^{[151]}$ and the BBB. ${ }^{[135,152]}$ Damage to epithelia from US has been reported, especially with low-frequency US, but seems to be largely reversible. ${ }^{[143-144,151]}$

3.3.2.3. Iontophoresis and electroporation: Iontophoresis, where an electric current is applied to the skin to drive the diffusive flow of ions through skin, can deliver hydrophilic 
and/or charged molecules across the SC ${ }^{[115-118]}$ A physical transdermal drug delivery system for transcutaneous flux of lidocaine and epinephrine for local dermal analgesia via iontophoresis was approved by the US FDA. ${ }^{[34,153]}$

During iontophoresis, a small direct (DC) or alternating current (AC) is applied for several minutes (with voltage typically less than $100 \mathrm{~V}$ and current density typically less than 0.5 $\mathrm{mA} \mathrm{cm}{ }^{-2}$ ). Iontophoresis does not primarily change the properties of the SC. Charged molecules (up to $12 \mathrm{kDa}$ ) are driven by an electric field and take the path of least resistance, such as through hair follicles. ${ }^{[116-117,119]}$ Charge-neutral molecules can be moved by the electroosmotic flow of water (or other bulk solvent) in the presence of electrolytes. ${ }^{[116-117,119,154]}$ Iontophoresis enables dosing controllable by adjusting the electric current. Iontophoretic transdermal delivery has been commercialized for the delivery of anesthetics and analgesics. [117, 120-121]

Electroporation refers to the use of high voltages (>100 V on skin; $0.3-1.0 \mathrm{~V}$ on cells) for short durations (microseconds to milliseconds) to reversibly disrupt the SC and deliver large compounds (e.g., nucleic acids, cytokines, peptides, and proteins, etc.). ${ }^{[114,122]}$ Unlike iontophoresis (which does not change the properties of the SC), electroporation is believed to generate hydrophilic pores that can last for hours within the SC. ${ }^{[122]}$ The disruption is limited to the SC, where the electrical resistance is orders of magnitude greater than in the rest of the skin. Structural changes in the SC are usually reversible and toxicologically insignificant. ${ }^{[113-114]}$ However, long treatment sessions can cause extensive and irreversible damage to the SC and the lowered SC resistance may allow the electric field to damage sensory neurons in deeper tissues. ${ }^{[155]}$

3.3.2.4. Microneedles: Microneedles were first introduced as a mechanism to promote the transport of large and charged molecules that are difficult to deliver otherwise, through the creation of micro-sized conduits across the skin. Microneedles were initially fabricated using a silicon etching process. ${ }^{[153]}$ Now, microneedles can be micro-fabricated from a variety of materials, such as sugars, ${ }^{[156]}$ silicon, metals, or biodegradable polymers. ${ }^{[157]}$

Microneedles differ from conventional subcutaneous injections in two ways: (1) they usually only penetrate the epidermis instead of all the way through the dermis, and are thus relatively painless; $[111-112,153]$ (2) transdermal drug transport relies on diffusion driven by a difference in chemical potentials instead of convection driven by pressure difference. ${ }^{[111,158]}$

Microneedles are arranged in arrays or patches for ease of application, with a wide range of needle densities per area (e.g., 200 ${ }^{[159-160]}$ and $20000^{[160-161]}$ needles $\mathrm{cm}^{-2}$ ). Needles can be hollow or solid. Hollow needles are often conduits for a non-pressurized drug reservoir. Solid ones are used to merely create microscopic channels within the tissue; drug can be dry-coated onto premade needles, ${ }^{[161]}$ or incorporated within a dissolvable or biodegradable needle (made of materials such as hydroxy-propyl-methylcellulose ${ }^{[162]}$ and poly-lactide-coglycolide $[\text { PLGA }]^{[111]}$ ) and eluted upon skin insertion. 
Microneedles can deliver macromolecules and hydrophilic small molecules, including hormones ${ }^{[111,158]}$ hydrophilic drugs, ${ }^{[153,162]}$ genetic material (DNA, siRNA), ${ }^{[111-112]}$ and vaccines. ${ }^{[110-111]}$ The drug molecules delivered via microneedles can enter the systemic circulation by absorption into capillaries in the dermis. Donepezil hydrochloride, for example, has been encapsulated within dissolvable needles and eluted into the blood stream for the treatment of Alzheimer's Disease. ${ }^{[162]}$ In another example, silicon microneedle arrays have delivered a cholesterol-modified housekeeping gene (Gapdh) siRNA across the $\mathrm{SC}$ in vivo. ${ }^{[112]}$ Greater plasma concentrations have been reported using microneedles than those obtained by oral administration for the same dose. ${ }^{[162]}$

Potential limitations of microneedles include patient discomfort (pain scores vary from 5 to $40 \%$ of those from hypodermic needles ${ }^{[163]}$ ) and limited drug loading. ${ }^{[111]}$ Pain could be addressed by optimizing the needle dimensions to avoid nerve endings. ${ }^{[111,161-162]}$ There is an upper limit of drug loading per needle, beyond which needle breakage can occur. ${ }^{[111]}$ Therefore, microneedles are considered most appropriate for highly potent drugs. However, high systemic drug concentrations (hundreds of micrograms per milliliter in plasma) of small-molecule drugs (e.g. ibuprofen) can be achieved using needles that are designed to break upon application and stay in skin after application. ${ }^{[164]}$ This high plasma drug concentration was achieved with needle patches of $\sim 2 \mathrm{~cm}^{2}$ applied to rats weighing $\sim 340 \mathrm{~g}$.

3.3.2.5. Magnetophoresis: Magnetophoresis uses a stationary magnetic field (5-450 mT), sometimes in combination with magnetic particles as drug carriers, to enhance transdermal drug delivery. ${ }^{[126]}$

Under a stationary magnetic field, the following two mechanisms dominate skin penetration. ${ }^{[126]}$ Magnetorepulsion, the force exerted by the applied magnetic field on drug carriers such as magnetic nanoparticles ${ }^{[126-127]}$, can push the drug through skin. Movement of water and drug molecules under the external magnetic field is due to diamagnetism, a quantum mechanical effect that occurs in all materials and induces magnetic fields in the opposite direction to an externally applied magnetic field. This movement can carry hydrophilic drugs across tissues such as the epidermis. Little, if any, lasting effect has been observed on the SC. ${ }^{[126-127]}$

A magnetophoretic transdermal patch consisting of a drug reservoir with magnetic backing has been used to deliver lidocaine across rat skin in vivo, and achieved about a two fold increase in the SC permeability to lidocaine. ${ }^{[126,128]}$ Magnets have also been combined with other physical enhancement mechanisms to increase molecular transport. In one example, magnetophoresis and nanosecond pulsed lasers were employed simultaneously to promote cellular transfection of siRNA. ${ }^{[125]}$

Permeation enhancement by physical means tends to be greater than by CPEs (Section 3.3.1), especially for macromolecules and nanoparticles. The physical means can also cause pain. However, the potential damage and pain are usually transient. It is difficult to compare the physical means among themselves, as the effectiveness/irritation depends on parameters such as laser intensity, electric current, or needles per unit area, which cannot be easily converted or translated from one method to another. 
3.3.3. Biomolecule-Mediated Enhancement-Many biomolecules can enhance drug flux across skin. (They also affect flux across other tissues, often by different mechanisms, as is described in the relevant sections.) They can do so by direct physicochemical effects on skin (analogous to the effects of CPEs), or by affecting its biochemistry so as to break down skin components or inhibit repair, disrupt tight junctions, or digest proteins.

3.3.3.1. Peptides as skin permeation enhancers: Skin-penetrating peptides (SPPs) include cell-penetrating peptides (CPPs), antimicrobial peptides (AMPs), and phage peptides. SPPs can penetrate skin through the lipid bilayers, and/or through corneocytes, and/or though hair follicles. ${ }^{[165]}$ Peptides which can break down skin or inhibit repair of the SC also act as skin permeation enhancers (See section 3.3.3.2).

Cell-Penetrating Peptides: Cell-penetrating peptides (CPPs) are usually around 30 amino acids in length, positively charged, and/or amphipathic. ${ }^{[166]} \mathrm{CPPs}$ were first derived from the transactivator of transcription (TAT) protein, which can cross cell membranes and cause transactivation of a viral promotor. ${ }^{[166]}$ CPPs are among the most studied SPPs.

CPPs have been successfully used to enhance skin penetration of therapeutics and cargoes including proteins, oligonucleotides and nanoparticles. ${ }^{[165]}$ Polyarginine (specifically, with 7 arginine amino acids, i.e. R7), one of the most studied CPPs, can penetrate the SC and reach the dermis of mouse skin. ${ }^{[167]} \mathrm{R} 7$ peptide has been used to enhance the transdermal delivery of the drug cyclosporine A (CsA) by forming the conjugate R7-CsA with a pH-sensitive covalent linker, which releases CsA at physiologic $\mathrm{pH}$. R7-CsA applied topically can reach dermal $\mathrm{T}$ lymphocytes and reduce cutaneous inflammation. Commonly studied CPPs include polyarginine (with 7-9 arginine amino acids), TAT, YKA, YARA, RALA, and penetratin (Figure 6).

The skin-penetration mechanism of CPPs is unclear. Spectroscopy suggests that the RALA peptide changes the lipid bilayers in the SC from a hexagonal arrangement (crystalline) to an amorphous structure which could result in an enhancement of skin penetration. ${ }^{[168]}$

Antimicrobial Peptides: Antimicrobial peptides (AMPs) usually contain less than 100 amino acids and can have broad-spectrum activity against bacteria, viruses, and fungi by creating pores in their lipid membranes. ${ }^{[165]}$ This property led to their application as permeation enhancers for skin. For example, magainin, a 23-amino acid peptide (Figure 6), is believed to form angstrom-scale pores in the lipid bilayers of the SC. ${ }^{[165]}$ A simple mixture of magainin and the small molecule CPE N-lauroylsarcosine achieved 35- to 92-fold increase in the delivery rate of fluorescein across human epidermis in vitro. ${ }^{[169-170]}$

Phage Peptides: Phage peptides are obtained by phage display technology, ${ }^{[171]}$ where a random peptide is displayed on each phage particle and libraries of such peptides can be screened for skin penetration. The peptide's amino acid sequence is critical to its effectiveness for transdermal delivery.

Among the first transdermal phage peptides reported was TD-1, an 11-amino acid cyclic peptide (ACSSSPSKHCG) identified by in vivo screening of peptide libraries for the ability 
to penetrate mouse skin. ${ }^{[172-173]}$ TD-1 could enhance the transdermal delivery of insulin when co-administered topically, lowering the serum glucose level in rats. TD-1 peptide has also been used to increase the transdermal delivery of other macromolecules such as hGH, ${ }^{[172,174]}$ siRNA, ${ }^{[175]}$ botulinum neurotoxin type A (BoNT-A), ${ }^{[176]}$ and CsA. ${ }^{[177]}$ The mechanism by which TD-1 penetrates the SC is unclear. ${ }^{[175]}$ TD-1 has been shown to also disrupt tight junctions (see Section 3.1) by interacting with the $\mathrm{Na}^{+} / \mathrm{K}^{+}$-ATPase beta-subunit (ATP1B1) on keratinocytes. ${ }^{[178]}$ TD-1 can also enable the transdermal delivery of macromolecular drugs such as insulin through hair follicles. ${ }^{[172]}$

The skin penetrating and cell entering (SPACE) peptide (cyclic ACTGSTQHQCG) was identified by screening peptide libraries for the ability to penetrate porcine skin in Franz diffusion cells, ${ }^{[179]}$ and was later proven effective in mice and humans. Cargoes such as small molecules, proteins, and genetic materials can be conjugated to the SPACE peptide and their biological function remains intact after penetrating skin. For example, the topically delivered conjugate SPACE-siRNA led to efficient knockout of targeted proteins both in vitro (in endothelial cells) and in vivo (in mouse skin). ${ }^{[179]}$ The SPACE peptide was found to be less toxic than R7 and TD-1 to keratinocytes. A permeation study using CsA demonstrated that SPACE can bind keratin and CsA concurrently, and thus enhance the partitioning of CsA into the keratin-rich corneocytes and increase the permeation rate. ${ }^{[177]}$ Based on this mechanism, a computational algorithm was developed to generate and screen virtual libraries of cyclic peptides containing disulfide bond(s) for affinity to both skin keratin and CsA. ${ }^{[180]}$ A new cyclic peptide (ACNAHQARSTCG) selected using this method showed significantly greater transdermal CsA delivery compared to the original SPACE peptide.

A linear 6-amino acid peptide (T2 peptide, LVGVFH) was identified via ex vivo phage display using porcine skin. ${ }^{[181]} \mathrm{T} 2$ peptide enhanced skin penetration of the hydrophilic drug 5-fluorouracil (5-FU). T2 peptide could interact with the lipid bilayers in the SC and cause conformational changes in the acyl chains of the lipids, enhancing the partitioning of small molecules with a range of lipophilicities into the skin. Another linear heptapeptide (DRTTLTN) was recently selected via ex vivo phage display using human skin. ${ }^{[182]}$ The peptide could penetrate the SC lipids by fluidization of the lipid bilayers and/or penetrate through corneocytes by altering the protein structure of keratin. Unfractionated heparin (UFH) conjugated to the DRTTLTN peptide has been delivered across human skin. ${ }^{[182]}$

\subsubsection{Molecules with specific biological functions: Molecules that break down} components of skin or inhibit the repair of skin can enhance transdermal permeability. The barrier function of SC can be reduced by lipid synthesis inhibitors. Peptides and enzymes that degrade keratin in the $\mathrm{SC}$ or tight junction proteins have also achieved skin permeation enhancement.

Lipid Synthesis Inhibitors: The SC lipid bilayers are the major transport barrier for transdermal drug delivery. Therefore, inhibition of lipid synthesis can delay the recovery of the lipid barrier function after permeabilization. ${ }^{[183]}$ Application of the fatty acid synthesis inhibitor 5-(tetradecyloxy)-2-furancarboxylic acid and the cholesterol synthesis inhibitors fluvastatin or cholesterol sulfate caused a significant increase in both duration and 
magnitude of transdermal delivery of lidocaine or caffeine after disruption of the skin barrier by acetone or DMSO. ${ }^{[184]}$

Regulators of Tight Junctions: Tight junctions directly underneath the SC become the major transport barrier when the SC is disrupted (e.g., in atopic dermatitis). $\left.{ }^{[3}\right] \mathrm{A}$ short synthetic peptide (FCIGRL, AT1002) was found to induce tight junction disassembly. ${ }^{[185]}$ Tight junction disruption by AT1002 increased transport of siRNA across the epithelial barrier in vivo in mice whose SC had been removed by a tape-stripping method. ${ }^{[33]}$

Enzymes: Trypsin, a proteolytic enzyme, has been used to pre-treat skin before a patch containing bovine insulin was applied. Trypsin enhanced the penetration of insulin, resulting in reduction of blood glucose levels in rats. ${ }^{[186]}$ Mechanistic studies suggested that trypsin could disturb the structure of keratin in the SC via proteolysis but appeared to have no effect on the lipid bilayers. ${ }^{[186]}$ Trypsin can also enhance the transdermal permeation of other macromolecules such as FITC-labelled dextrans and FITC-insulin. ${ }^{[187]}$ Enzymes that degrade other components of the epidermis (e.g. hyaluronidase to degrade hyaluronic acid) have also been used to extend the spread through tissue of injected molecules such as local anesthetics. ${ }^{[188]}$

Biomolecule-mediated enhancement has several advantages compare to physical/chemical means: 1) the effect is often localized at the targeted location, with little to no damage to the surrounding tissues; 2) the design of biomolecules can be adapted to overcome barrier at other anatomic locations (see Sections 5.2 and 5.4 for more details). The development of tissue-penetrating biomolecules is still in its infancy, with a long way ahead toward clinical practice.

\section{Nanoparticles}

Encapsulation in nanoparticles has been used to enhance the penetration of drugs into tissues. Also, there are conditions and approaches that can be exploited to enhance nanoparticle penetration into tissues (Section 6), resulting in increased drug delivery. The uses of nanoparticles in penetrating specific tissues are covered in the subsections pertaining to those tissues.

\subsection{Enhancement of Drug Delivery by Nanoencapsulation}

Nanoparticles can enhance drug penetration in some contexts, particularly where enhanced permeation and retention (EPR) is in effect (Section 4.2), and in porous structures such as mucus (Section 5.2). ${ }^{[189]}$ In skin, the ability to penetrate the SC and reach viable epidermis is limited for most unmodified nanoparticles by themselves. The transcellular route along hair follicles (Fig. 2) has been considered the main path of passive diffusion for nanoparticles. $^{[25]}$

Nanoscale liposomes (vesicular structures composed of lipids ${ }^{[190]}$ ) have demonstrated better skin penetration than most other nanoparticles. ${ }^{[191]}$ Liposomes with the structural flexibility to deform and squeeze through the intercellular lipid bilayers demonstrated greater skin 
penetration than rigid liposomes. ${ }^{[192-193]}$ siRNA has been successfully delivered through intact human SC using deformable liposomes. ${ }^{[194]}$

\subsection{Enhancement of Drug Flux by Improving Nanoparticle Delivery}

Disruption of normal tissue architecture can enhance penetration of nanoparticles, and consequently of the encapsulated drugs. For example, the blood vessels of tumors are leaky compared to normal blood vessels because the endothelial cells of tumor vessels have intercellular openings (ranging from hundreds of nanometers to 1-2 micrometers) and loose interconnections, and their lymphatics are defective. ${ }^{[195]}$ These properties of tumors lead to the EPR of macromolecules (including drugs and plasma proteins), ${ }^{[196]}$ lipid particles, ${ }^{[196]}$ and nanoparticles of a certain size (typically in the range of tens to hundreds of nanometers). ${ }^{[197]}$ The EPR effect has been commonly used to enhance penetration of therapeutics into tumors in animal models, ${ }^{[198]}$ although the effect is highly variable in humans. ${ }^{[199]}$ The use of EPR is intended to lead to a preferential accumulation of drug in tumors (vs. in normal tissue); whether that occurs is controversial. ${ }^{[200]}$ EPR-like effects have also been observed in atherosclerosis, where chronic inflammation of arterial blood vessels leads to rapid proliferation of endothelial cells and formation of leaky and defective blood vessels, ${ }^{[201]}$ and following experimental myocardial infarction, where disruption of the vasculature presumably renders it leaky. ${ }^{[202]}$

The size and surface functionalization of nanoparticles both influence transport properties within tissues. In general, smaller particles have shown better penetration through endothelia and into tumor tissue, although sub-10-nm nanoparticles tend to have relatively short halflives after intravenous injection due to rapid renal clearance. ${ }^{[203-205]}$ Nanoparticles tens to hundreds of nanometers in diameter and with minimal surface charge can extravasate from the abnormal vasculature found in tumors but not the normal vasculature (except, for example, in organs which normally have a permeable vasculature, as in the liver). ${ }^{[198]}$ One clear demonstration of the effect of size was done with nanoparticles that could be induced to shrink in situ from 150 to $40 \mathrm{~nm}$ in diameter upon UV irradiation. After UV irradiation, greater penetration of the nanoparticles into tumors was observed. ${ }^{[204,206]}$ Interestingly, the particle shrinkage also enhanced nanoparticle penetration in intact rabbit corneas. ${ }^{210}$

Delivery of nanoparticles can be enhanced by reversible disruption of the SC. Surface modification with macromolecular CPEs have been used for this purpose. ${ }^{[207]}$ Hyaluronatemodified nanorods ( $\sim 16 \mathrm{~nm}$ diameter and $\sim 91 \mathrm{~nm}$ in length) were used to deliver an antitumor drug (death receptor 5 antibody) across the epidermis after topical application in murine model of skin cancer. ${ }^{[207]}$ The drug was conjugated to the nanoparticle surface. Penetration of nanoparticles into the dermis was demonstrated by two-photon microscopy using fluorescently-labeled death receptor 5 antibody. The antibody alone could not penetrate the SC.

Physical methods have also been employed to enable nanoparticles to cross skin. Solid silicon microneedles ( $150 \mu \mathrm{m}$ length and $80 \mu \mathrm{m}$ diameter) were applied to cadaver skin to create microscopic pores. After the microneedles were removed, a solution of polystyrene particles $50 \mathrm{~nm}$ in radius was applied to skin and shown to permeate skin at $10^{-3}-10^{-4} \mathrm{~cm} / \mathrm{h}$; while no nanoparticles permeated skin without microneedles. ${ }^{[208]}$ Iontophoresis (current 
density $0.50 \mathrm{~mA} / \mathrm{cm}^{2}$; pulse frequency $2000 \mathrm{~Hz} ; 1: 1$ pulse on/off interval ratio) was used to deliver solid lipid nanoparticles (100-800 $\mathrm{nm}$ diameter) containing triamcinolone acetonide acetate (a glucocorticoid agonist) across porcine skin. Delivery by iontophoresis of nanoparticles enhanced flux across skin 3-7 fold over that for the free drug. ${ }^{[209]}$

Poly(ethylene glycol) (PEG) can be used to modify particle surfaces to enhance permeation by minimizing interaction with the surrounding environment in vivo, such as in mucus. ${ }^{\text {[210] }}$ Surface modification with PEG has improved the rate of diffusion of polystyrene nanoparticles ranging 100 to $500 \mathrm{~nm}$ in diameter in undiluted human mucus by up to 3 orders of magnitude, ex vivo. ${ }^{[210]}$

Barrier crossing by nanoparticles can be enhanced simply by making the particles more available to cross. One very common example of this is nanoparticle PEGylation, which can minimize the adsorption of serum proteins on the particle surface, reduce their uptake by the reticuloendothelial systems, and prolong their blood circulation time. ${ }^{[211-212]}$ The prolonged residence time, when combined with targeting mechanisms, can result in greater amounts of drugs that overcome a biological barrier, such as the BBB, than that of nanoparticles without PEGylation. Therapeutic genes (e.g., antisense mRNA against the human epidermal growth factor receptor gene) have been delivered into an intracranial mouse model of a brain tumor by intravenous injection. The therapeutic genes were encapsulated in PEGylated liposomes functionalized with receptor-specific monoclonal antibodies targeting the mouse transferrin receptor that enables cross-BBB delivery. ${ }^{[213]}$

\section{Breaching Biological Barriers other than Skin}

Permeation enhancement methods other than those designed for skin have been employed to cross other biological barriers. Here we discuss a selection of such tissues, chosen to provide a broad perspective of the types of approaches that have been developed.

\subsection{Trans-Tympanic Drug Delivery}

Drug delivery across the tympanic membrane (TM) can be done via methods similar to those developed for skin. The TM is a tri-layer membrane whose outer layer is a stratified squamous keratinizing epithelium continuous with the skin of the external auditory canal. The innermost layer is a simple cuboidal mucosal epithelium. Between these epithelia is a layer of fibro-elastic connective tissue and associated blood vessels and nerves. The human TM is only about $100 \mu \mathrm{m}$-thick, but the 6-10 cell layer outer epithelium forms an impenetrable barrier against all but small and moderately lipophilic molecules due to its keratin- and lipid-rich SC. ${ }^{[214]}$ Because of this structural similarity to skin, the delivery platforms developed for transdermal delivery may be transferrable to trans-tympanic delivery.

Localized and sustained drug delivery directly to the middle ear (Figure 7) for conditions such as otitis media have several advantages over systemic application. Since the drug would go directly to the middle ear, there would be much less systemic distribution of drug and therefore fewer side effects (which can limit therapy) and perhaps less inducement for antibiotic resistant bacteria. If it were possible to pack an entire treatment regimen into one 
applied dose, it would not be necessary for parents to struggle to deliver an oral dose to uncooperative toddlers three times a day for ten days. However, otic gel preparations for non-invasive drug delivery across the TM have not been explored until recently due to the impermeability of the TM. (Similar considerations apply to the inner ear and Ménière's disease, with the round window being the principal barrier to drug delivery, assuming the drug is placed in the middle ear.) CPEs have been used to deliver drugs across the $\mathrm{TM},{ }^{[9]}$ where a broad-spectrum antibiotic, ciprofloxacin, was delivered directly into the middle ear to treat otitis media (Figure 7B)..$\left.^{3}\right]$ Sustained trans-tympanic drug transport has been realized with CPEs contained within a hydrogel (Figure 7). ${ }^{[3,9]}$ Peptides that can cross the TM of rats with otitis media (induced by nontypeable Haemophilus influenza) have also been identified via phage display. ${ }^{[215]}$

Iron oxide nanoparticles have been encapsulated in PLGA and used to deliver therapeutics such as dexamethasone across the round window and into the inner ear under an external magnetic field $(0.26 \mathrm{mT}){ }^{[216-217]}$

\subsection{Mucus-Penetrating Nanoparticles}

Mucus is commonly found on surfaces of the respiratory tract, GI tract, female genital tract, nasal passages, and eyes. Drug delivery across mucus and to mucosal surfaces can be important in the local treatment of numerous conditions. ${ }^{[218]}$

Human mucus is on average tens to hundreds of micrometers thick and composed of disulfide bond cross-linked fibers composed of 0.5 to $50 \mathrm{MDa}$ mucins, entangled with other biomacromolecules including DNA and glycoproteins. ${ }^{[219]}$ Despite having over $90 \%$ water content, mucus has a viscosity that is $10^{3}$ to $10^{4}$ times higher than that of water at low shear rates. $[218,220]$

Mucins are high molecular weight glycoproteins, where blocks of serine, threonine, or proline (glycosylated with, for example, fucose, galactose, sialic acid, $\mathrm{N}$-acetylglucosamine, and $\mathrm{N}$-acetylgalactosamine) make up $\sim 80 \%$ of the protein backbones. ${ }^{[221-222]}$ The glycosylated regions of mucins are hydrophilic and negatively charged, allowing small hydrophilic molecules, such as glucuronic acid and mannitol, to pass through mucus quickly. ${ }^{[22]}$ Interestingly, given the anionic domains of the mucins, the charge of molecules does not have a clear effect on their diffusivity in mucus. ${ }^{[223-224]}$ The non-glycosylated regions are hydrophobic and can trap hydrophobic molecules (such as testosterone) or hydrophobic particles. ${ }^{[223,225]}$

Some viruses, particularly ones less than $100 \mathrm{~nm}$ in diameter, of neutral charge, and with hydrophilic surfaces (e.g., human papilloma virus, $55 \mathrm{~nm}$ in size), can diffuse through mucus as easily as through water). ${ }^{[226]}$ This rapid penetration has been explained by envisioning mucus as a "sticky" net with a pore size of $100 \mathrm{~nm} .^{[226-227]}$ Diffusion coefficients in mucus decrease rapidly as the particle diameter rises above $100 \mathrm{~nm} .{ }^{[224,226]}$ Consequently, nanoparticles smaller than $100 \mathrm{~nm}$ are most commonly used. The permeability of particles with diameters of $270 \mathrm{~nm}$ or $490 \mathrm{~nm}$ is only $18 \%$ or $3 \%$ respectively of particles $70 \mathrm{~nm}$ in diameter. ${ }^{[24]}$ 
Nanoparticles used as mucus-penetrating delivery vehicles are generally hydrophilic and neutrally charged; ${ }^{[218]}$ the same is true of drugs that penetrated mucus (in contrast to the properties that are advantageous in crossing skin). Modification of the surface of nanoparticles with hydrophilic and neutrally charged PEG improved their penetration of mucus. ${ }^{[218]}$ For example, poloxamer 407 (a block copolymer rich in PEG blocks) coating of $65 \mathrm{~nm}$ nanoparticles containing acyclovir monophosphate greatly enhanced penetration into mucus. ${ }^{[228]}$

Mucolytic agents, such as $\mathrm{N}$-acetylcysteine, ${ }^{[229]}$ nacystelyn, ${ }^{[230]}$ and gelsolin, ${ }^{[231]}$ may be used to enhance particle transport. Mucolytics disentangle the cross-linked mucus network and reduce the viscoelasticity of mucus. ${ }^{[232]}$ However, mucolytics tend to have an unpleasant odor. ${ }^{[233]}$ There is considerable variability from patient to patient in the effectiveness of mucolytics in breaking down mucus. ${ }^{[234-235]}$

Hydrophilic nanoparticles that can penetrate mucus are in clinical trials to deliver loteprednol etabonate to the eye for the treatment of dry eye disease and for post-surgical inflammation and pain. ${ }^{[236]}$

\subsection{Trans-GI Tract Delivery}

The human GI tract consists of the stomach, small intestine, and large intestine. The small intestine has a large surface area $\left(200 \mathrm{~m}^{2}\right)$ and is the main site of absorption for most drugs taken orally. ${ }^{[237]}$ However, the absorption of macromolecules (such as insulin, antibodies, and genetic materials) in the GI tract is challenging because the cells of the intestinal epithelium are connected by tight junctions. ${ }^{[238]}$ Macromolecules are also susceptible to enzymatic degradation in the GI tract. (Proteins are normally a chopped up by peptidases in the intestinal lumen and the resulting peptides are absorbed; the body then synthesizes what proteins are needed de novo. $)^{[238]}$ Flux of many drugs into the body is counteracted by efflux transporters on the apical (luminal) membrane of GI epithelial cells, such as the pglycoprotein multidrug transporter, which actively eject drugs from the body after uptake into enterocytes (see below for methods of overcoming). ${ }^{[239-241]}$

Orally-administered fatty acids have been used for trans-GI drug delivery. ${ }^{[242]}$ For example, sodium caprate has been demonstrated to disrupt tight junctions transiently in the GI tract in several animal models, and caused no tissue damage even after repeated oral administration. ${ }^{[243-245]}$ It may also function as a conventional CPE. ${ }^{[246]}$ Sodium caprate is approved by the FDA as a direct food additive for human consumption. ${ }^{[247]}$ It was welltolerated and effective in humans in a number of clinical studies, where the GI absorption of various drugs (e.g., alendronate, zoledronic acid, ampicillin, cefoxitin, ceftizoxime, acyline, and oligonucleotides) were enhanced. ${ }^{[242]}$ Sodium caprate has been used to deliver antisense oligonucleotides. For example, the antisense oligonucleotide to tumor necrosis factor a mRNA was formulated with sodium caprate in a tablet and administered to healthy volunteers orally, resulting in a plasma bioavailability of around $9.5 \% .{ }^{[248]}$ This formulation [presumably] has undergone a Phase 3 clinical trial in gastrointestinal autoimmune disease. ${ }^{[249]}$ 
An amino acid derivative of sodium caprylate (sodium N-[8-(2-hydroxybenzoyl) amino] caprylate [SNAC]) has also been tested in clinical trials for the oral delivery of a variety of substances including ibandronate, ${ }^{[250]}$ cyanocobalamin (Vitamin B-12), ${ }^{[251]}$ glucagon-like peptide $1,{ }^{[252]}$ and insulin. ${ }^{[253]}$ For example, glucagon-like peptide 1 and peptide YY 3-36 (both of which reduce food consumption) have been mixed with SNAC and formulated into a tablet administered orally to healthy volunteers. ${ }^{[252]}$ This oral formulation led to peak plasma concentrations of $\sim 30 \mathrm{pmol} / \mathrm{L}$ and $398 \mathrm{pg} / \mathrm{mL}$ respectively for glucagon-like peptide 1 (dosed at $2 \mathrm{mg}$ ) and peptide YY 3-36 (dosed at $1 \mathrm{mg}$ ) and reduced total energy intake by $21.5 \%$ on average in humans. ${ }^{[252]}$ The mechanism of permeation enhancement for SNAC is unclear. One theory is that it can form a non-covalent complex with the therapeutic agent, providing protection against intestinal degradation while also promoting absorption in the GI tract. ${ }^{[254-255]}$ CPEs undergoing clinical trials for trans-GI delivery have been reviewed elsewhere. ${ }^{[254]}$

Chitosan can also enhance trans-GI drug delivery by loosening tight junctions via electrostatic interactions with negatively charged GI mucosal epithelia. ${ }^{[256]}$ Insulin has been conjugated to trimethyl chitosan and administered orally to healthy rats, which induced hypoglycemia (with blood glucose levels reduced to $80 \%$ those of rats not given the drug) for 8 hours after administration. ${ }^{[257]}$

Flux of proteins across the GI tract can also be enhanced by immobilization of a drug delivery system within the lumen. For example, insulin-loaded polymeric microparticles containing magnetic particles were maintained in the intestines of mice by having them wear a miniature magnetic vest. ${ }^{[258]}$ This approach resulted in increased insulin uptake compared to the same formulation without the magnetic vest.

Ultrasound can induce transient cavitation in tight junctions in the rectal epithelium and enhance trans-GI delivery of therapeutics, as indicated in a number of pre-clinical studies. For example, a more than 20 -fold enhancement of drug permeation compared to a conventional enema has been achieved by applying a 1-minute treatment of low-frequency ultrasound generated by a rectal probe in Yorkshire pigs. ${ }^{[259]}$ Similar enhancement can be achieved for the delivery of hydrocortisone and mesalamine. ${ }^{[136]}$

Microneedle-based approaches have been suggested for GI delivery of drugs. For example, a pill concept has been reported that would deploy microneedles. ${ }^{[260]}$

Nanoparticles have been used to deliver drugs via the GI tract. ${ }^{[261]}$ For example, the hydrophobic molecule quercetin has been loaded in solid lipid nanoparticles made of glyceryl monostearate and soya lecithin, with a diameter of $\sim 155 \mathrm{~nm}$, and administered orally in healthy rats. ${ }^{[262]}$ The peak plasma concentration of quercetin was doubled and the elimination half-life tripled when delivered in the lipid nanoparticles compared to free drug at the same dose. ${ }^{[262]}$

Efflux inhibitors can reduce the efflux of drugs by p-glycoprotein transporters located on the apical cell membranes of the GI epithelia and improve overall trans-GI permeation of therapeutics. P-glycoprotein inhibitors have been under investigation for more than three decades. ${ }^{[239]}$ However, the commonly used inhibitors, such as verapamil, dexverapamil, 
dexniguldipin, and tariquidar, have not been successful in clinical trials due to severe side effects observed in cancer patients (such as acute congestive heart failure, nausea, vomiting, and depression in the case of dexverapamil, dexniguldipin, and tariquidar) and/or lack of beneficial effect (verapamil). ${ }^{[239,263]}$

There has been a recent focus on screening products of natural origin (e.g. flavonoids from fruits), inspired by the observation that grapefruit juice can increase the oral bioavailability and effects, both adverse and advantageous, of the dihydropyridine calcium channel antagonists, felodipine and nifedipine. ${ }^{[264]}$ For example quercetin, a flavonoid found in fruits, vegetables, leaves and grains, increased the bioavailability of oral doxorubicin in rats, which was attributed to enhanced absorption in the GI tract via inhibition of pglycoprotein. ${ }^{[265]}$

The administration of biomacromolecules via the oral route remains a major challenge in drug delivery. In current clinical practice, oral administration of biomacromolecules is limited to low-MW peptides. Oral administration of macromolecules with MW above 5000 $\mathrm{Da}$, such as insulin, remains a challenge.

Concerns have been raised about the safety of enhancing the permeability of the GI. The incidence of autoimmune diseases has been correlated with the consumption of food additives that increase intestinal permeability. ${ }^{[266]}$ It has been hypothesized that increased permeability of the GI tract results in the entry ofimmunogenic antigens and causes autoimmunity. ${ }^{[266]}$ Surfactant CPEs can impair the protective mucus layer, facilitating the diffusion of luminal bacteria to the intestinal epithelium and ultimately disturbing the host microbiota. For example, CPEs polysorbate- 80 and carboxymethyl cellulose have been shown to disturb microbiota composition and induce obesity in mice. ${ }^{[267]}$ Repeated administration of the macromolecular CPE chitosan (Section 3.3.1.2) caused alterations in gut microbiota in healthy volunteers. ${ }^{[268]}$

\subsection{Enhancement of Drug Permeation of the Blood-Brain Barrier}

The BBB is the capillary bed of the brain, which controls the exchange of substances between the blood and the fluids (cerebrospinal fluid and brain interstitial fluid) bathing the central nervous system (CNS). ${ }^{[269]}$ The capillary endothelial cells are connected by tight junctions, which provide the barrier function. $[4,270]$

For a substance to enter the CNS, it must traverse the endothelium and partition into the aqueous environment of the cerebrospinal fluid and/or brain interstitial fluid. The degree to which a substance can undergo passive diffusion across the BBB is dictated by its molecular weight and $\log P{ }^{[271]}$ Macromolecules or small molecules with $\operatorname{low} \log P$ (i.e. hydrophilic) cannot cross the BBB passively; molecules with high $\log \mathrm{P}$ also have difficulty crossing as they tend to be trapped in the cell membranes. The ideal molecular weights and $\log P$ s for crossing the BBB are less than $400-500 \mathrm{Da}^{[272]}$ and between 1 and 2 respectively. [269] Charge also has an effect on diffusion across BBB by the changing partition of the substance between aqueous and lipid environments; molecules with obligate charge can have difficult crossing the BBB. Uptake of weak bases by the cerebrospinal fluid is favored compared to acids because the cerebrospinal fluid is slightly more acidic than plasma. ${ }^{[269]}$ In silico 
models have been developed for predicting the effect of physicochemical properties of a substance on its BBB permeability. ${ }^{\text {273-274] }}$

Some of the strategies discussed in Sections 3 and 4 have been use to disrupt the BBB for drug delivery. ${ }^{[269]}$ Ultrasound alone applied to the skull in rabbits increased the permeation of MRI contrast agent across the BBB. ${ }^{[275]}$ Ultrasound combined with intravenously injected 1.1-3.3 $\mu \mathrm{m}$ microbubbles (a proprietary formulation of octafluoropropane [gas] in a lipid shell, to enhance the effect of ultrasound on BBB permeability) have been used to induce BBB disruption in monkeys enhanced permeation of MRI contrast agent (Gd-DPTA) into the brain was demonstrated. ${ }^{[276]}$

The structural integrity of tight junctions can be broken transiently and reversibly by shrinkage of BBB endothelial cells by osmotic shock. ${ }^{[277]}$ Hypertonic solutions, such as a solution of mannitol, have been administered via intra-arterial infusion for this purpose. The resulting separation of endothelial cells enhanced permeability across the BBB. ${ }^{[277]}$ Carboplatin and etoposide delivered in conjunction with osmotic shock (from mannitol infused in the vertebral artery) seemed to have - according to the authors - some therapeutic benefit, but many of the patients experienced irreversible hearing loss. ${ }^{[277-278]}$ The permeation enhancement achieved by physical effects is non-selective with respect to compounds that are allowed to cross the BBB and could theoretically let in circulating substances that are toxic to the CNS.

Approaches taking advantage of the BBB's own mechanisms for taking up specific substances could achieve selective delivery of therapeutics across the BBB without letting in other substances. These strategies include: 1) adsorptive transcytosis and 2) receptormediated transcytosis.

Adsorptive transcytosis is induced by the binding of highly positively charged molecules (such as cell-penetrating peptides; Section 3.3.3.1) to negatively charged regions on the BBB endothelial cell membrane (e.g. glycoproteins), which leads to the formation of vesicles routed into the cell with subsequent exocytosis on the abluminal surface ${ }^{[279]}$ Many cationic molecules, including cell-penetrating peptides (Section 3.3.3.1), hexamethylenediamine, protamine, and poly-L-lysine, have been mixed with or conjugated onto proteins (e.g., albumin, insulin, histone, and antibodies) and enhanced the flux of these proteins across the BBB in vivo in pre-clinical studies. ${ }^{[279-280]}$ For example, $\beta$-galactosidase has been fused to a TAT (trans-activator of transcription)-derived peptide and administered into mice by intraperitoneal injection. The biologically active fusion protein was delivered to all tissues including the brain; the enzymatic activity of the fusion protein in the brain was confirmed by the X-Gal assay. ${ }^{[280]}$

To the best of our knowledge, drug delivery across the BBB based on adsorptive transcytosis has not entered human clinical trials. Drawbacks of this approach can include that adsorptive transcytosis is not cell-or even tissue-specific, which can cause systemic toxicity. ${ }^{[279]}$ For example, poly-L-arginine peptides have been shown to induce inflammation in rat lungs after intraperitoneal injection. ${ }^{[281]}$ 
Receptor-mediated transcytosis utilizes transporters in the BBB to carry therapeutics across. Transporters are proteins found on both apical and luminal surfaces of BBB endothelial cells that allow specific substances to be carried from one side of the BBB to the other. ${ }^{[4]}$ The endogenous transporters can be categorized into 1) carrier-mediated transporters; 2) receptor-mediated transporters; 3 ) active efflux transporters. ${ }^{[4]}$

Carrier-mediated transporters are responsible for transporting small-molecule nutrients and endogenous compounds into the brain ${ }^{[282-283]}$ including, separately, hexose sugars, neutral amino acids, acidic amino acids, basic amino acids, $\beta$-amino acids, monocarboxylic acids, choline and thiamine, nucleosides, peptides, and others. Carrier-mediated transporter systems have been used for drug delivery. For example, L-dopa uses the large neutral amino acid type 1 transporter (LAT1) to cross the BBB. ${ }^{[284-285]}$ Once inside the brain, L-dopa is decarboxylated by aromatic amino acid decarboxylase to generate the native dopamine.

Receptor-mediated transporters can transport macromolecules (e.g., insulin, iron-transferrin, low-density lipoprotein, cytokines, oligonucleotide analogues, ${ }^{[4,269,279]}$ ) across the BBB. Therapeutic molecules (usually macromolecules) can be conjugated to these macromolecular ligands to the receptor-mediated transporters, enabling their transport across the BBB. Numerous analogues of the endogenous ligands, or of peptidomimetic antibodies (i.e. antibodies designed to mimic a peptide) that bind and activate the receptor-mediated transporters have been developed for drug delivery over three decades of research, ${ }^{[286]}$ with numerous animal studies performed including in primates. (Such ligands are sometimes referred to as "molecular Trojan horses" because of their ability to ferry conjugated drugs across the BBB.) In one example, an antibody against $\beta$-secretase (BACE1) for the treatment of Alzheimer's disease has been delivered to the brains of mice and non-human primates by conjugation with an antibody against transferrin receptors in the BBB. ${ }^{[287]}$ Intravenous injection of the protein conjugate resulted in sustained reductions in $A \beta$ concentrations in the central nervous system in mice and monkeys. ${ }^{[287]}$ In another example of a molecular Trojan horse, the enzyme iduronate 2-sulfatase, used to treat mucopolysaccharidosis Type II has been fused with a monoclonal antibody targeted to the human insulin receptor so that the enzyme would be transported across the BBB. The brain uptake of the enzyme was $1 \%$ of the injected dose, 34-fold that without the conjugated antibody. ${ }^{[288]}$ After 26 weeks of weekly intravenous administration in juvenile male Rhesus monkeys, no adverse events (e.g., immune response, tissue injury) were observed. ${ }^{[289]}$

Concerns have been raised over the potential effects of impairing or competing with function of the transporters. It has been suggested that a ligand (e.g. an antibody) targeted to a region of the transporter that is not directly involved in binding to the endogenous ligand may resolve this issue. By doing this, the delivery system (e.g. therapeutic proteins fused with targeting antibodies) will not interfere with the normal function of the transporters. [286, 290]

Efflux transporters (brain-to-blood transporters) have been discovered for a large variety of molecules, including ions, amino acids, peptides, and cytokines. ${ }^{\left[{ }^{[69]}\right.}$ The efflux caused by these transporters may be so robust that they may not be overcome by some flux enhancement methods (e.g. via BBB disruption). ${ }^{[291-292]}$ P-glycoprotein, which can cause efflux of molecules ranging from lipids and peptides to anticancer drugs (such as 
anthracyclines and taxanes) and immunosuppressive agents (e.g. CsA), is a major cause of failure for many therapeutics targeted at the CNS. Inhibition of P-glycoprotein by verapamil has been used with drugs that are known to be efflux substrates of P-glycoprotein (including phenobarbital, topiramate, levetiracetam, phenytoin, and lamotrigine). In an epileptic dog model, verapamil was ineffective as it did not affect phenobarbital concentrations in plasma or cerebrospinal fluid, and caused side effects including bradycardia, decreased blood pressure, and worsening of seizure control; ${ }^{[293]}$ it has been speculated that the worsened seizure control could be due to impairment of the removal of toxic metabolites from brain to blood inhibition by P-glycoprotein. ${ }^{[291]}$ Nevertheless, verapamil, when taken with topiramate, levetiracetam, phenytoin, lamotrigine, reduced the frequency of seizures in pediatric patients. ${ }^{[294]}$ Future research in this area may address inhibition of more specific efflux systems (e.g. ones that influence a narrower range of molecules).

Another example of inhibiting an efflux systems is seen in using an antisense oligonucleotide to the PTS-6 efflux transporter. Use of that oligonucleotide enabled delivery to the brain of intravenously administered pituitary adenylate cyclase-activating polypeptide 27 (PACAP27). Brain retention of PACAP27 increased by about fourfold and there was a $30-40 \%$ reduction in the number of trials a mouse needed to avoid foot shock in a maze in murine models of stroke and Alzheimer disease. ${ }^{[295]}$

\section{Conditions with Altered Tissue Permeability}

The penetration of therapeutics or delivery vehicles (Section 4.1) into tissues can be enhanced by the disruption of normal tissue structure in some diseased states.

Skin infections often disrupt the structural integrity of the SC and lead to increased transdermal permeation. Atopic dermatitis has been shown to cause a nearly 10 -fold increase in SC permeability in patients aged 4 months to 18 years. ${ }^{[296]}$ Interestingly, the uninvolved skin areas (i.e., skin without visible infection and/or inflammation) of atopic dermatitis patients have a permeability twice that of skin in healthy volunteers. ${ }^{[296]}$ Increased permeability to drugs has also been observed in the tympanic membranes of animals with otitis media. ${ }^{[3]}$ In a chinchilla animal model, the diffusion coefficient of the tympanic membranes with otitis increased to 10 - to 15 -fold of that in healthy tympanic membranes.

Increased permeation in diseased states has been observed for the BBB as well. ${ }^{[269]}$ Many meningeal pathogens can induce an inflammatory response, such as increased expression of TNF-a systemically, which correlates with enhanced permeability of the BBB, allowing enhanced cross-BBB permeaiton of drugs. ${ }^{[297-298]}$ A transient increase in BBB permeability to Evans Blue has been observed following traumatic brain injury in rats. ${ }^{[299]}$ The BBB also becomes disrupted in diabetic humans and animal models. ${ }^{[300-301]}$ Increased mitochondrial oxidative stress, which is commonly observed in diabetes, can induce loss of BBB pericytes, ${ }^{[300-301]}$ cells that regulate the BBB and whose loss induces BBB disruption and increased permeability of the BBB to water, small molecules (e.g. Evans Blue), and macromolecules (e.g. dextran, bovine serum albumin, and $\operatorname{IgG}$ ). ${ }^{[302]}$ 
Altered tissue permeability can also be induced. For example, penetration of the cationic local anesthetic tetrodotoxin into peripheral nerves was enhanced by osmotic shock with hypertonic saline. ${ }^{[303]}$

\section{Conclusions}

The transdermal delivery of small, moderately lipophilic therapeutics has become a common clinical practice. The US FDA has approved more than a dozen CPEs as safe excipients, and physical enhancement methods, such as iontophoresis and ultrasound, have also made their way to the clinic for the treatment of inflammation and pain. ${ }^{\left[{ }^{[3]}\right.}$ In general, the most successful systems are likely to be the simplest, and/or those that also address a secondary need (secondary to the delivery of the drug itself). As an example of such as secondary goal, patches may be advantageous in settings where patient compliance is inconvenient or oral delivery is difficult for practical (e.g. inability to eat/drink) or pharmacological (e.g. avoiding first-pass effect) reasons. More complex or inconvenient approaches, perhaps even requiring contact with the medical system, may be necessary with payloads that are difficult to get across biological barriers, as they may require more specialized equipment.

Interest in crossing specific barriers tends to shift as new technologies are discovered and investigators try to use them to address a particular problem. Another potent driving force is probably entrepreneurial zeal: when study of delivery to a particular tissue or of a class of drug is saturated, there is often a push to discover opportunities in new areas. However, the success of transdermal systems in penetrating into clinical practice has not always been seen with other types of systems in other organs. One of the more perplexing questions for researchers who are casually interested in technologies that help drugs cross barriers is why formulations that seems so promising in one or more publications seem to vanish without a trace, and the corollary to that, which is why - if an approach is really so promising - it has not penetrated into clinical practice yet. There are many relatively tangible potential reasons for failure to achieve clinical application. Some of the potential scientific reasons have been outlined above, including that the efficacy and toxicity of treatments may be poorly understood. What is cool science is not always practical medicine, and what seemed a good idea at the bench actually may not have been. (It would be interesting to study the relationship between the impact factor or other metric of the journal that a new technology is published in and the extent of the technology's penetration into the clinical arena.) In many cases, the payloads that one might want to deliver across a barrier (such as protein drugs, nucleic acids, nanoparticles) might themselves be relatively new or even under development themselves. In some such cases, the technologies are therefore essentially in search of an application. In other circumstances, a technology may fail simply because there is an existing method that is generally good enough (a pill or even a subcutaneous injection).

There are numerous non-biomedical factors that can slow clinical adoption of these technologies. There is the Scylla and Charybdis of patentability and regulatory considerations; both are fairly opaque matters to the uninitiated. The more novel an approach, the easier to patent and therefore the easier to build a company, reassure investors, etc. However, the same novelty may result in a longer regulatory pathway, which may entail more extensive toxicity studies, more numerous and more extensive clinical trials - all of 
which translate into increased cost (money) and longer time to market (and time, as we all know, is money). The medical system tends to be slow to accept novel technologies, and there is often the issue of whether a third-party payer would pay for this technology were it to be commercialized.

There are other reasons that technologies vanish which we can only refer to anecdotally. There is a portion of scientific inquiry that is irreproducible, but that lack of reproducibility is rarely documented. Even if the lack of reproducibility is identified, it may not be possible to elucidate why it happens. Sometimes particular results are dominated by the technical idiosyncrasies of an investigator (e.g. an injection technique that inadvertently injects drug directly into a nerve, not next to it, giving the incorrect impression that a formulation works well). There is also a tendency in some to publish only the experiments that worked, not the entire set of experiments; this gives the misleading impression that something that sometimes works is a proven approach. Part of the problem is laxity in deciding which data points count (i.e. deciding which data can be excluded as "outliers" - always a decision potentially fraught with bias). Another potential problem is a misunderstanding of what constitutes proof. These difficulties rarely make their way into print, partly because there is little motivation for people to reproduce others' work unless it is of intense and widespread interest and/or there is suspicion of fraud.

The balance between effectiveness and toxicity is an important consideration in designing drug delivery systems to overcome biological barriers. For virtually all of the approaches discussed in Section 3, the more effective ones resulted in more tissue toxicity. One potential way to address this dilemma might be to use a combination of approaches that each increase flux but have different toxicities. Such systems could potentially have additive or even synergistic activity without a commensurate increase in toxicity. It bears mentioning that many reports cite the synergistic nature of observed interactions without actually doing the experimentation and analysis needed to use that term properly. ${ }^{[304]}$

Approaches to getting drugs across barriers within the body other than skin tend to be more complex. A major problem with many of these approaches is in proving that they actually work, which in a medical context means that they achieve a therapeutic goal without too much toxicity. (The related concept in medicine is the therapeutic index, the ratio between the drug dose/concentration needed for effect and the dose/concentration that causes toxicity however defined.) In transdermal delivery, such issues are relatively simple since metrics of success (e.g. blood levels of drug) are relatively well-understood and easy to measure, as is the toxicity (e.g. histological changes). Moreover, skin is a relatively tough and resilient tissue. In contrast, it may be hard to understand the significance of a given drug level in a particular part of other organs (e.g. brain), and the significance of induced local disruptions in tissue architecture (e.g. loosening of the blood-brain barrier). These difficulties may be part of the reason why, despite decades of research, means of enhancing drug flux into some tissues have not entered clinical practice.

Another obstacle to translation is that some systems are not tested in vivo, where they may not perform as ideally as they did in vitro. (In this respect, this field has been somewhat better than others, perhaps because of the relative simplicity of some of the models, such as 
transdermal delivery.) It is also obviously important to ensure relevance of a model to its human analogue; e.g. in the magnitude to which it presents a barrier to penetration, whether it has the same receptor systems for drug uptake, etc.

Delivery of macromolecules across biological barriers remains a challenge. It is difficult for small-molecule CPEs to create the relatively large pores that would allow the diffusion of macromolecules. Physical methods such as ultrasound can enable the delivery of macromolecules by causing micron-scale disruptions in the tissue. Even with such methods however, the relatively low diffusivity of high molecular weight compounds can impede delivery. ${ }^{[305]}$ The combination of various modalities of enhancing flux may be beneficial. For example, the combination of micron-scale disruption (e.g. by microneedles) with an added driving force, such as ultrasound has been described. ${ }^{[306]}$

Drug delivery systems in general are becoming more sophisticated, and it is likely that the same will be true of formulations that help drugs cross barriers. ${ }^{[32]}$ For example, there is considerable interest in systems that allow on-demand drug delivery and/or programmability. ${ }^{[307-309]}$ These systems, often referred to as stimulus-responsive or triggered, could employ a wide variety of energy sources to initiate drug release - from lasers and ultrasound to manual contact. ${ }^{[307-309]}$ They have recently been applied to transdermal drug delivery. For example, a patch has been developed where the microneedles are melted by application of near infrared light, inducing on-demand delivery of doxorubicin hydrochloride across rat skin. ${ }^{[310]}$ Also, a patch made of temperature sensitive poly (N-vinyl caprolactam) was used to encapsulate acetamidophenol and etoricoxib; local heating led to delivery across rat skin. ${ }^{[311]}$ Moreover, the energy sources used as stimuli could enhance the effectiveness of more traditional approaches such as CPEs ${ }^{[312]}$ For example, electroporation $(100 \mathrm{~V} ; 1 \mathrm{~Hz} ; 1 \mathrm{~ms}$ duration; 5 pulses in total) increased the permeation enhancement ratio of $0.2 \% \mathrm{w} / \mathrm{v}$ SDS from 1.8 to 37.3 , measured by the cumulative glucose permeated across porcine epidermis in 12 hours. ${ }^{[313]}$

As the complexity of the delivery systems increases, it is possible that regulatory hurdles will increase accordingly. In developing new systems, it will be important to maintain focus on simplicity (to the extent possible), cost-effectiveness, and patient-friendliness. The latter is particularly important since the primary motivations behind many formulations described in this review were convenience, avoidance of pain, and improvement of patient compliance.

\section{Acknowledgments}

This work was financially supported by NIH DC015050 to D.S.K., and Trailblazer Research Grant by the Department of Anesthesia at Boston Children's Hospital and Charles H. Hood Foundation Child Health Research Award to R.Y

\section{References}

1. Sagie I, Kohane DS. Proc. Natl. Acad. Sci. U. S. A. 2010; 107:3740. [PubMed: 20133669]

2. Simons EJ, Bellas E, Lawlor MW, Kohane DS. Mol. Pharm. 2009; 6:265. [PubMed: 19105721]

3. Yang R, Sabharwal V, Okonkwo OS, Shlykova N, Tong R, Lin LY, Wang W, Guo S, Rosowski JJ, Pelton SI, Kohane DS. Sci. Transl. Med. 2016; 8:356ra120.

4. Pardridge WM. NeuroRx. 2005; 2:3. [PubMed: 15717053] 
5. Torchilin VP. Annu. Rev. Biomed. Eng. 2006; 8:343. [PubMed: 16834560]

6. Panyam J, Labhasetwar V. Adv. Drug Deliv. Rev. 2003; 55:329. [PubMed: 12628320]

7. Bareford LM, Swaan PW. Adv. Drug Deliv. Rev. 2007; 59:748. [PubMed: 17659804]

8. Williams AC, Barry BW. Adv. Drug Deliv. Rev. 2012; 64:128.

9. Khoo X, Simons EJ, Chiang HH, Hickey JM, Sabharwal V, Pelton SI, Rosowski JJ, Langer R, Kohane DS. Biomaterials. 2013; 34:1281. [PubMed: 23146430]

10. Wang L, Shankarappa SA, Tong R, Ciolino JB, Tsui JH, Chiang HH, Kohane DS. Cornea. 2013; 32:1040. [PubMed: 23615270]

11. Sassaroli E, O’Neill B. Phys. Med. Biol. 2014; 59:6775. [PubMed: 25327766]

12. Lopez RF, Seto JE, Blankschtein D, Langer R. Biomaterials. 2011; 32:933. [PubMed: 20971504]

13. Ng S-F, Rouse JJ, Sanderson FD, Meidan V, Eccleston GM. AAPS Pharm Sci Tech. 2010; 11:1432.

14. Pade V, Stavchansky S. J. Pharm. Sci. 1998; 87:1604. [PubMed: 10189274]

15. Winton H, Wan H, Cannell M, Gruenert D, Thompson P, Garrod D, Stewart G, Robinson C. Clin. Exp. Allergy. 1998; 28:1273. [PubMed: 9824395]

16. Sung JH, Esch MB, Prot J-M, Long CJ, Smith A, Hickman JJ, Shuler ML. Lab Chip. 2013; 13:1201. [PubMed: 23388858]

17. Tojo K, Isowaki A. Adv. Drug Deliv. Rev. 2001; 52:17. [PubMed: 11672872]

18. Yeo Y, Burdick JA, Highley CB, Marini R, Langer R, Kohane DS. J. Biomed. Mater. Res. A. 2006; 78:668. [PubMed: 16739173]

19. Bartosova L, Bajgar J. Curr. Med. Chem. 2012; 19:4671. [PubMed: 22934776]

20. Ciolino JB, Stefanescu CF, Ross AE, Salvador-Culla B, Cortez P, Ford EM, Wymbs KA, Sprague SL, Mascoop DR, Rudina SS. Biomaterials. 2014; 35:432. [PubMed: 24094935]

21. Kohane DS, Langer R. Chem. Sci. 2010; 1:441.

22. Bélanger MC, Marois Y. J. Biomed. Mater. Res. A. 2001; 58:467.

23. Magner, LN. A history of medicine. CRC Press; 1992.

24. Pastore MN, Kalia YN, Horstmann M, Roberts MS. Br. J. Pharmacol. 2015; 172:2179. [PubMed: 25560046]

25. Ryan, E., Grice, JE., Roberts, MS. Nanotechnology and Drug Delivery, Volume Two: NanoEngineering Strategies and Nanomedicines against Severe Diseases. CRC Press; 2016. p. 75

26. Brown MB, Martin GP, Jones SA, Akomeah FK. Drug Deliv. 2006; 13:175. [PubMed: 16556569]

27. Enander I, Nilsen M, Lillieborg TS. Acta Derm. Venereol. 1990; 70:227. [PubMed: 1972836]

28. Watkinson AC, Kearney M-C, Quinn HL, Courtenay AJ, Donnelly RF. Expert Opin. Drug Deliv. 2016; 13:523. [PubMed: 26646399]

29. Elias PM. J. Gen. Intern. Med. 2005; 20:183.

30. Heisig M, Lieckfeldt R, Wittum G, Mazurkevich G, Lee G. Pharm. Res. 1996; 13:421. [PubMed: 8692735]

31. Herman A, Herman AP. J. Pharm. Pharmacol. 2015; 67:473. [PubMed: 25557808]

32. Prausnitz MR, Langer R. Nat. Biotechnol. 2008; 26:1261. [PubMed: 18997767]

33. Uchida T, Kanazawa T, Takashima Y, Okada H. Chem. Pharm. Bull. 2011; 59:196. [PubMed: 21297299]

34. FDA. Approved Drug Products with Therapeutic Equivalence Evaluations. Rockville, MD: 2016. 35. Evans HC, Easthope SE. Drugs. 2003; 63:1999. [PubMed: 12962515]

36. Douglas, J. The Washington Post. Washington D.C.: 2006.

37. Mather L. Clin. Pharmacokinet. 1983; 8:422. [PubMed: 6226471]

38. Nelson L, Schwaner R. J. Med. Toxicol. 2009; 5:230. [PubMed: 19876859]

39. Venkatraman, SS., Li, S., Gale, RM., Stepic, J., Van Osdol, WW. Google Patents. 2008.

40. Sebel P, Barrett C, Kirk C, Heykants J. Eur. J. Clin. Pharmacol. 1987; 32:529. [PubMed: 2957211]

41. Tezel A, Sens A, Mitragotri S. J. Pharm. Sci. 2003; 92:381. [PubMed: 12532387]

42. Karande P, Jain A, Mitragotri S. Nat. Biotechnol. 2004; 22:192. [PubMed: 14704682]

Adv Mater. Author manuscript; available in PMC 2018 October 01. 
43. Prausnitz MR. Adv. Drug Deliv. Rev. 2004; 56:581. [PubMed: 15019747]

44. Foldvari M, Babiuk S, Badea I. Curr Drug Deliv. 2006; 3:17. [PubMed: 16472090]

45. Hsu T, Mitragotri S. Proc. Natl. Acad. Sci. U.S.A. 2011; 108:15816. [PubMed: 21903933]

46. FDA. Inactive Ingredients Database. 2016

47. Bhatt PP, Hanna MS, Szeptycki P, Takeru H. Int. J. Pharm. 1989; 50:197.

48. Sintov AC, Krymberk I, Daniel D, Hannan T, Sohn Ze, Levin G. J. Control. Release. 2003; 89:311. [PubMed: 12711453]

49. Karande P, Jain A, Ergun K, Kispersky V, Mitragotri S. Proc. Natl. Acad. Sci. USA. 2005; 102:4688. [PubMed: 15774584]

50. Pilgram G, Van Der Meulen J, Gooris G, Koerten H, Bouwstra J. BBA Biomembranes. 2001; 1511:244. [PubMed: 11286967]

51. Ongpipattanakul B, Burnette RR, Potts RO, Francoeur ML. Pharm. Res. 1991; 8:350. [PubMed: 2052523]

52. Tanojo H, Bos-van Geest A, Bouwstra JA, Junginger HE, Boodé HE. Thermochim. Acta. 1997; 293:77.

53. Cornwell PA, Barry BW, Bouwstra JA, Gooris GS. Int. J. Pharm. 1996; 127:9.

54. Berner B, Mazzenga GC, Otte JH, Steffens RJ, Juang R-H, Ebert CD. J. Pharm. Sci. 1989; 78:402. [PubMed: 2501473]

55. Oertel RP. Biopolymers. 1977; 16:2329. [PubMed: 912004]

56. Anigbogu AN, Williams AC, Barry BW, Edwards HG. Int. J. Pharm. 1995; 125:265.

57. Aungst BJ, Rogers NJ, Shefter E. Int. J. Pharm. 1986; 33:225.

58. Aungst BJ. Pharm. Res. 1989; 6:244. [PubMed: 2726682]

59. Tupker R, Pinnagoda J, Nater J. Acta Derm. Venereol. 1989; 70:1.

60. Watkinson A, Green D, Brain K, James V, Walters K, Azri-Meehan S, Sharma R, Dressler W. Perspectives in Percutaneous Penetration. 1997; 5:54.

61. Gordon WP, Forte AJ, McMurtry RJ, Gal J, Nelson SD. Toxicol. Appl. Pharmacol. 1982; 65:413. [PubMed: 7157374]

62. Wiechers JW, De Zeeuw R. Drug Des. Deliv. 1990; 6:87. [PubMed: 2080983]

63. Allan, G. Percutaneous Penetration Enhancers. Smith, EW., Maibach, HI., editors. CRC Press; Boca Raton, Florida: 1995.

64. Dragicevic, N., Maibach, HI. Percutaneous Penetration Enhancers Chemical Methods in Penetration Enhancement: Drug Manipulation Strategies and Vehicle Effects. Springer; Berlin, Heidelberg: 2015.

65. Karande P, Jain A, Mitragotri S. J. Control. Release. 2006; 115:85. [PubMed: 16935378]

66. Stern R. Eur. J. Cell Biol. 2004; 83:317. [PubMed: 15503855]

67. Brown M, Jones SA. J Eur Acad Dermatol Venereol. 2005; 19:308. [PubMed: 15857456]

68. Jung HS, Kim KS, Yun SH, Hahn SK. Nanomedicine. 2014; 9:743. [PubMed: 24981644]

69. Yang J-A, Kim E-S, Kwon JH, Kim H, Shin JH, Yun SH, Choi KY, Hahn SK. Biomaterials. 2012; 33:5947. [PubMed: 22632765]

70. Jung HS, Kong WH, Sung DK, Lee M-Y, Beack SE, Keum DH, Kim KS, Yun SH, Hahn SK. ACS nano. 2014; 8:260. [PubMed: 24383990]

71. Beack S, Kong WH, Jung HS, Do IH, Han S, Kim H, Kim KS, Yun SH, Hahn SK. Acta Biomater. 2015; 26:295. [PubMed: 26297888]

72. Kong WH, Sung DK, Kim H, Yang J-A, Ieronimakis N, Kim KS, Lee J, Kim D-H, Yun SH, Hahn SK. Biomaterials. 2016; 81:93. [PubMed: 26724457]

73. Kim KS, Kim H, Park Y, Kong WH, Lee SW, Kwok SJ, Hahn SK, Yun SH. Adv Funct Mater. 2016; 26:2512. [PubMed: 27833475]

74. Kong M, Chen XG, Kweon DK, Park HJ. Carbohydr. Polym. 2011; 86:837.

75. Witting M, Boreham A, Brodwolf R, Vávrová Ki, Alexiev U, Friess W, Hedtrich S. Mol Pharm. 2015; 12:1391. [PubMed: 25871518] 
76. Wang Z, Itoh Y, Hosaka Y, Kobayashi I, Nakano Y, Maeda I, Umeda F, Yamakawa J, Kawase M, Yag K. J Biosci Bioeng. 2003; 95:541. [PubMed: 16233454]

77. Yiyun C, Na M, Tongwen X, Rongqiang F, Xueyuan W, Xiaomin W, Longping W. J Pharm Sci. 2007; 96:595. [PubMed: 17094130]

78. Borowska K, Laskowska B, Magoń A, Mysliwiec B, Pyda M, Wołowiec S. Int J Pharm. 2010; 398:185. [PubMed: 20655371]

79. Filipowicz A, Wołowiec S. Int J Pharm. 2011; 408:152. [PubMed: 21272625]

80. Venuganti VVK, Perumal OP. Int J Pharm. 2008; 361:230. [PubMed: 18582550]

81. Chauhan AS, Sridevi S, Chalasani KB, Jain AK, Jain SK, Jain N, Diwan PV. J Control Release. 2003; 90:335. [PubMed: 12880700]

82. Bielinska AU, Yen A, Wu HL, Zahos KM, Sun R, Weiner ND, Baker JR, Roessler BJ. Biomaterials. 2000; 21:877. [PubMed: 10735464]

83. Sun M, Fan A, Wang Z, Zhao Y. Soft Matter. 2012; 8:4301.

84. Yang Y, Sunoqrot S, Stowell C, Ji J, Lee C-W, Kim JW, Khan SA, Hong S. Biomacromolecules. 2012; 13:2154. [PubMed: 22621160]

85. Barry BW. Nat Biotechnol. 2004; 22:165. [PubMed: 14755286]

86. Cheng Y, Zhao L, Li T. Soft Matter. 2014; 10:2714. [PubMed: 24668313]

87. He X, Qu Z, Xu F, Lin M, Wang J, Shi X, Lu T. Soft Matter. 2014; 10:139. [PubMed: 24651532]

88. Mignani S, El Kazzouli S, Bousmina M, Majoral J-P. Adv. Drug Deliv. Rev. 2013; 65:1316. [PubMed: 23415951]

89. Yang J, Hu J, He B, Cheng Y. Expert Opin Ther Pat. 2015; 25:1209. [PubMed: 26150049]

90. Venuganti VV, Sahdev P, Hildreth M, Guan X, Perumal O. Pharm. Res. 2011; 28:2246. [PubMed: 21633876]

91. Crini G. Chem Rev. 2014; 114:10940. [PubMed: 25247843]

92. Sá Couto, A., Salústio, P., Cabral-Marques, H. Polysaccharides: Bioactivity and Biotechnology.

Ramawat, GK., Mérillon, J-M., editors. Springer International Publishing; Cham: 2015. p. 247

93. Palem CR, Siva C, Subrahmanyam P, Rao Y. Curr Trends Biotechnol Pharm. 2012; 6:255.

94. Loftsson, T. Percutaneous Penetration Enhancers Chemical Methods in Penetration Enhancement. Dragicevic, N., Maibach, HI., editors. Springer; Berlin, Heidelberg: 2015. p. 189

95. Shimpi S, Chauhan B, Shimpi P. Acta Pharm. 2005; 55:139. [PubMed: 16179128]

96. Loftsson T, Vogensen SB, Brewster ME, Konráđsdóttir F. J Pharm Sci. 2007; 96:2532. [PubMed: 17630644]

97. Lipinski CA, Lombardo F, Dominy BW, Feeney PJ. Adv. Drug Deliv. Rev. 2012; 64:4.

98. Loftsson T, Jarho P, Masson M, Järvinen T. Expert Opin. Drug Deliv. 2005; 2:335. [PubMed: 16296758]

99. Matsuda H, Arima H. Adv. Drug Deliv. Rev. 1999; 36:81. [PubMed: 10837710]

100. Irie T, Uekama K. J Pharm Sci. 1997; 86:147. [PubMed: 9040088]

101. Chen Y, Wang M, Fang L. Drug Deliv. 2013; 20:199. [PubMed: 23763451]

102. Ghanghoria R, Kesharwani P, Agashe HB, Jain N. Drug Deliv. Transl. Res. 2013; 3:272. [PubMed: 25788135]

103. Legendre J, Rault I, Petit A, Luijten W, Demuynck I, Horvath S, Ginot Y, Cuine A. Eur J Pharm Sci. 1995; 3:311.

104. Huang Z, London E. Langmuir. 2013; 29:14631. [PubMed: 24175704]

105. Loftsson T, Másson M, Sigurdsson H, Magnusson P, Le Goffic F. Pharmazie. 1998; 53:137. [PubMed: 9540112]

106. Zhou X, Liu D, Liu H, Yang Q, Yao K, Wang X, Wang L, Yang X. J Pharm Sci. 2010; 99:2991. [PubMed: 20091820]

107. He W, Guo X, Zhang M. Int J Pharm. 2008; 356:82. [PubMed: 18337030]

108. He W, Guo X, Xiao L, Feng M. Int J Pharm. 2009; 382:234. [PubMed: 19686826]

109. Lv H-X, Zhang Z-H, Wang X-P, Cheng Q-Q, Wang W, Huang X-H, Zhou J-P, Zhang Q, Hou L-L, Huo W. Molecules. 2011; 16:6778. [PubMed: 21829153] 
110. Chu LY, Ye L, Dong K, Compans RW, Yang C, Prausnitz MR. Pharm. Res. 2016; 33:868. [PubMed: 26620313]

111. Park J-H, Allen MG, Prausnitz MR. Pharm. Res. 2006; 23:1008. [PubMed: 16715391]

112. Deng Y, Chen J, Zhao Y, Yan X, Zhang L, Choy K, Hu J, Sant HJ, Gale BK, Tang T. Sci. Rep. 2016; 6:21422. [PubMed: 26888011]

113. Daud AI, DeConti RC, Andrews S, Urbas P, Riker AI, Sondak VK, Munster PN, Sullivan DM, Ugen KE, Messina JL. J. Clin. Oncol. 2008; 26:5896. [PubMed: 19029422]

114. Denet A-R, Vanbever R, Préat V. Adv. Drug Deliv. Rev. 2004; 56:659. [PubMed: 15019751]

115. Tavakoli N, Minaiyan M, Heshmatipour M, Musavinasab R. Res. Pharm. Sci. 2015; 10:419. [PubMed: 26752990]

116. Sieg A, Guy RH, Delgado-Charro MB. Biophys. J. 2004; 87:3344. [PubMed: 15339817]

117. Rawat S, Vengurlekar S, Rakesh B, Jain S, Srikarti G. Indian J. Pharm. Sci. 2008; 70:5. [PubMed: 20390073]

118. Dubey S, Kalia Y. J. Control. Release. 2010; 145:203. [PubMed: 20423719]

119. Guy RH, Kalia YN, Delgado-Charro MB, Merino V, Lopez A, Marro D. J. Control. Release. 2000; 64:129. [PubMed: 10640651]

120. Maloney JM. Arch. Dermatol. 1992; 128:331. [PubMed: 1550364]

121. Stephen R, Petelenz T, Jacobsen S. Biomed. Biochim. Acta. 1983; 43:553.

122. Sammeta SM, Vaka SRK, Murthy SN. J. Control. Release. 2010; 142:361. [PubMed: 19922748]

123. Marshall W, Boone BA, Burgos JD, Gografe SI, Baldwin MK, Danielson ML, Larson MJ, Caretto DR, Cruz Y, Ferraro B. Gene Ther. 2010; 17:419. [PubMed: 19956270]

124. Huang H, Guo Z. J. Phys. D: Appl. Phys. 2009; 42:165204.

125. Babincová M, Babincová N, Durdík S, Bergemann C, Sourivong P. Laser Phys. Lett. 2016; 13:065601.

126. Murthy SN, Sammeta SM, Bowers C. J. Control. Release. 2010; 148:197. [PubMed: 20728484]

127. Chen A-Z, Chen L-Q, Wang S-B, Wang Y-Q, Zha J-Z. Int. J. Nanomedicine. 2015; 10:4639. [PubMed: 26229467]

128. Sammeta SM, Repka MA, Narasimha Murthy S. Drug Dev. Ind. Pharm. 2011; 37:1076. [PubMed: 21449699]

129. Lee WR, Shen SC, Fang CL, Zhuo RZ, Fang JY. Lasers Surg. Med. 2008; 40:468. [PubMed: 18727021]

130. Lin C-H, Aljuffali IA, Fang J-Y. Expert Opin. Drug Deliv. 2014; 11:599. [PubMed: 24490743]

131. Nelson JS, McCullough JL, Glenn TC, Wright WH, Liaw L-HL, Jacques SL. J. Invest. Dermatol. 1991; 97:874. [PubMed: 1919050]

132. Kalia Y, Bachhav Y, Bragagna T, Böhler C. Drug Deliv. Technol. 2008; 8:26.

133. Yu J, Bachhav Y, Summer S, Heinrich A, Bragagna T, Böhler C, Kalia Y. J. Control. Release. 2010; 148:e71. [PubMed: 21529638]

134. Niemz, MH. Laser-tissue interactions: fundamentals and applications. Springer Science \& Business Media; 2013.

135. Carpentier A, Canney M, Vignot A, Reina V, Beccaria K, Horodyckid C, Karachi C, Leclercq D, Lafon C, Chapelon J-Y. Sci. Transl. Med. 2016; 8:343re2.

136. Schoellhammer CM, Schroeder A, Maa R, Lauwers GY, Swiston A, Zervas M, Barman R, DiCiccio AM, Brugge WR, Anderson DG, Blankschtein D, Langer R, Traverso G. Sci. Transl. Med. 2015; 7:310ra168.

137. Jacques SL, McAuliffe DJ, Blank IH, Parrish JA. J. Invest. Dermatol. 1987; 88:88. [PubMed: 3794393]

138. Doukas AG, Kollias N. Adv. Drug Deliv. Rev. 2004; 56:559. [PubMed: 15019746]

139. Nawaz A, Wong TW. Carbohydr. Polym. 2017; 157:906. [PubMed: 27988008]

140. Tezel A, Sens A, Tuchscherer J, Mitragotri S. Pharm. Res. 2001; 18:1694. [PubMed: 11785688]

141. Prentice P, Cuschieri A, Dholakia K, Prausnitz M, Campbell P. Nature Phys. 2005; 1:107.

142. Schlicher RK, Radhakrishna H, Tolentino TP, Apkarian RP, Zarnitsyn V, Prausnitz MR. Ultrasound Med. Biol. 2006; 32:915. [PubMed: 16785013] 
143. Tachibana K, Tachibana S. Echocardiography. 2001; 18:323. [PubMed: 11415505]

144. Mitragotri S. Nat. Rev. Drug Discov. 2005; 4:255. [PubMed: 15738980]

145. Lewin PA, Bjo L. J. Acoust. Soc. Am. 1981; 69:846. [PubMed: 7240564]

146. Wu J. Ultrasound Med. Biol. 2002; 28:125. [PubMed: 11879959]

147. Qin S, Caskey CF, Ferrara KW. Phys. Med. Biol. 2009; 54:R27. [PubMed: 19229096]

148. Schoellhammer CM, Srinivasan S, Barman R, Mo SH, Polat BE, Langer R, Blankschtein D. J. Control. Release. 2015; 202:93. [PubMed: 25662228]

149. Azagury A, Khoury L, Enden G, Kost J. Adv. Drug Deliv. Rev. 2014; 72:127. [PubMed: 24463344]

150. Schoellhammer CM, Schroeder A, Maa R, Lauwers GY, Swiston A, Zervas M, Barman R, DiCiccio AM, Brugge WR, Anderson DG. Sci. Transl. Med. 2015; 7:310ra168.

151. Zderic V, Clark JI, Vaezy S. J. Ultrasound. Med. 2004; 23:1349. [PubMed: 15448325]

152. Hynynen K, McDannold N, Vykhodtseva N, Jolesz FA. Radiology. 2001; 220:640. [PubMed: 11526261]

153. Henry, S., McAllister, D., Allen, M., Prausnitz, M. Micromachined needles for the transdermal delivery of drugs; presented at Micro Electro Mechanical Systems, 1998. MEMS 98. Proceedings., The Eleventh Annual International Workshop on; 1998.

154. Pikal MJ. Adv. Drug Deliv. Rev. 2001; 46:281. [PubMed: 11259844]

155. Prausnitz MR. Adv. Drug Deliv. Rev. 1996; 18:395.

156. Miyano T, Tobinaga Y, Kanno T, Matsuzaki Y, Takeda H, Wakui M, Hanada K. Biomed Microdevices. 2005; 7:185. [PubMed: 16133805]

157. Garland MJ, Migalska K, Mahmood TMT, Singh TRR, Woolfson AD, Donnelly RF. Expert Rev. Med. Devices. 2011; 8:459. [PubMed: 21728732]

158. Daddona PE, Matriano JA, Mandema J, Maa Y-F. Pharm. Res. 2011; 28:159. [PubMed: 20567999]

159. Kaur M, Ita KB, Popova IE, Parikh SJ, Bair DA. Eur. J. Pharm. Biopharm. 2014; 86:284. [PubMed: 24176676]

160. Yan G, Warner KS, Zhang J, Sharma S, Gale BK. Int. J. Pharm. 2010; 391:7. [PubMed: 20188808]

161. Chen X, Prow TW, Crichton ML, Jenkins DWK, Roberts MS, Frazer IH, Fernando GJP, Kendall MAF. J. Control. Release. 2009; 139:212. [PubMed: 19577597]

162. Kim J-Y, Han M-R, Kim Y-H, Shin S-W, Nam S-Y, Park J-H. Eur. J. Pharm. Biopharm. 2016; 105:148. [PubMed: 27288938]

163. Gill HS, Denson DD, Burris BA, Prausnitz MR. Clin. J. Pain. 2008; 24:585. [PubMed: 18716497]

164. McCrudden MTC, Alkilani AZ, McCrudden CM, McAlister E, McCarthy HO, Woolfson AD, Donnelly RF. J. Control. Release. 2014; 180:71. [PubMed: 24556420]

165. Kumar, S., Narishetty, ST., Tummala, H. Percutaneous Penetration Enhancers Chemical Methods in Penetration Enhancement. Dragicevic, N., Maibach, IH., editors. Springer; Berlin, Heidelberg: 2015. p. 337

166. Koren E, Torchilin VP. Trends Mol. Med. 2012; 18:385. [PubMed: 22682515]

167. Rothbard JB, Garlington S, Lin Q, Kirschberg T, Kreider E, McGrane PL, Wender PA, Khavari PA. Nat. Med. 2000; 6:1253. [PubMed: 11062537]

168. Cohen-Avrahami M, Aserin A, Garti N. Colloids Surf., B. 2010; 77:131.

169. Kim Y-C, Late S, Banga AK, Ludovice PJ, Prausnitz MR. Int. J. Pharm. 2008; 362:20. [PubMed: 18601987]

170. Kim Y-C, Ludovice PJ, Prausnitz MR. J. Control. Release. 2007; 122:375. [PubMed: 17628164]

171. Haq IU, Chaudhry WN, Akhtar MN, Andleeb S, Qadri I. Virol. J. 2012; 9

172. Chen YP, Shen YY, Guo X, Zhang CS, Yang WJ, Ma ML, Liu S, Zhang MB, Wen LP. Nat. Biotechnol. 2006; 24:455. [PubMed: 16565728]

173. Ruan R, Chen M, Zou L, Wei P, Liu J, Ding W, Wen L. Ther. Deliv. 2016; 7:89. [PubMed: 26769200] 
174. Zhang T, Qu HY, Li XL, Zhao BQ, Zhou JP, Li QA, Sun MJ. J. Pharm. Sci. 2010; 99:4880. [PubMed: 20821386]

175. Lin C-M, Huang K, Zeng Y, Chen X-C, Wang S, Li Y. Arch. Dermatol. Res. 2012; 304:139. [PubMed: 22009459]

176. Carmichael NME, Dostrovsky JO, Charlton MP. Pain. 2010; 149:316. [PubMed: 20223589]

177. Kumar S, Zakrewsky M, Chen M, Menegatti S, Muraski JA, Mitragotri S. J. Control. Release. 2015; 199:168. [PubMed: 25499919]

178. Wang C, Ruan R, Zhang L, Zhang Y, Zhou W, Lin J, Ding W, Wen L. Mol. Pharm. 2015; 12:1259. [PubMed: 25734358]

179. Hsu T, Mitragotri S. Proc. Natl. Acad. Sci. USA. 2011; 108:15816. [PubMed: 21903933]

180. Menegatti S, Zakrewsky M, Kumar S, De Oliveira JS, Muraski JA, Mitragotri S. Adv. Healthc. Mater. 2016; 5:602. [PubMed: 26799634]

181. Kumar S, Sahdev P, Perumal O, Tummala H. Mol. Pharm. 2012; 9:1320. [PubMed: 22452335]

182. Gennari CGM, Franze S, Pellegrino S, Corsini E, Vistoli G, Montanari L, Minghetti P, Cilurzo F. Biomacromolecules. 2016; 17:46. [PubMed: 26623948]

183. Fang, L., Chen, Y. Percutaneous Penetration Enhancers Chemical Methods in Penetration Enhancement: Modification of the Stratum Corneum. Dragicevic, N., Maibach, IH., editors. Springer; Berlin, Heidelberg: 2015. p. 363

184. Tsai JC, Guy RH, Thornfeldt CR, Gao WN, Feingold KR, Elias PM. J. Pharm. Sci. 1996; 85:643. [PubMed: 8773963]

185. Gopalakrishnan S, Pandey N, Tamiz AP, Vere J, Carrasco R, Somerville R, Tripathi A, Ginski M, Paterson BM, Alkan SS. Int. J. Pharm. 2009; 365:121. [PubMed: 18832018]

186. Li, Y-z, Quan, Y-s, Zang, L., Jin, M-n, Kamiyama, F., Katsumi, H., Yamamoto, A., Tsutsumi, S. Biol. Pharm. Bull. 2008; 31:1574. [PubMed: 18670091]

187. Li, Y-z, Quan, Y-s, Zang, L., Jin, M-n, Kamiyama, F., Katsumi, H., Tsutsumi, S., Yamamoto, A. J. Pharm. Pharmacol. 2009; 61:1005. [PubMed: 19703343]

188. Eckenhoff JB, Kirby CK. Anesthesiology. 1951; 12:27. [PubMed: 14799895]

189. Barua S, Mitragotri S. Nano Today. 2014; 9:223. [PubMed: 25132862]

190. Santamaria CM, Woodruff A, Yang R, Kohane DS. Mater. Today. 2016 in print.

191. Lasch J, Laub R, Wohlrab W. J. Control. Release. 1992; 18:55.

192. Song Y-K, Kim C-K. Biomaterials. 2006; 27:271. [PubMed: 16039711]

193. Cevc G, Blume G. BBA Biomembranes. 2004; 1663:61. [PubMed: 15157608]

194. Geusens B, Van Gele M, Braat S, De Smedt SC, Stuart MC, Prow TW, Sanchez W, Roberts MS, Sanders NN, Lambert J. Adv. Funct. Mater. 2010; 20:4077.

195. McDonald DM, Baluk P. Cancer Res. 2002; 62:5381. [PubMed: 12235011]

196. Maeda H, Wu J, Sawa T, Matsumura Y, Hori K. J. Control. Release. 2000; 65:271. [PubMed: 10699287]

197. Petros RA, DeSimone JM. Nat Rev Drug Discov. 2010; 9:615. [PubMed: 20616808]

198. Davis ME, Shin DM. Nat. Rev. Drug Discov. 2008; 7:771. [PubMed: 18758474]

199. Lammers T. Int. J. Pharm. 2013; 454:527. [PubMed: 23485339]

200. Wilhelm S, Tavares AJ, Dai Q, Ohta S, Audet J, Dvorak HF, Chan WC. Nat. Rev. Mater. 2016; $1: 16014$.

201. Moulton KS, Olsen BR, Sonn S, Fukai N, Zurakowski D, Zeng X. Circulation. 2004; 110:1330. [PubMed: 15313955]

202. Dvir T, Bauer M, Schroeder A, Tsui JH, Anderson DG, Langer R, Liao R, Kohane DS. Nano Letters. 2011; 11:4411. [PubMed: 21899318]

203. Wong C, Stylianopoulos T, Cui J, Martin J, Chauhan VP, Jiang W, Popović Z, Jain RK, Bawendi MG, Fukumura D. Proc. Natl. Acad. Sci. U.S.A. 2011; 108:2426. [PubMed: 21245339]

204. Tong R, Hemmati HD, Langer R, Kohane DS. J Am Chem Soc. 2012; 134:8848. [PubMed: 22385538]

205. Blanco E, Shen H, Ferrari M. Nat Biotech. 2015; 33:941. 
206. Tong R, Chiang HH, Kohane DS. Proc. Natl. Acad. Sci. U.S.A. 2013; 110:19048. [PubMed: 24191048]

207. Lee H, Lee JH, Kim J, Mun JH, Chung J, Koo H, Kim C, Yun SH, Hahn SK. ACS Appl. Mater. Interfaces. 2016; 8:32202. [PubMed: 27933820]

208. McAllister DV, Wang PM, Davis SP, Park J-H, Canatella PJ, Allen MG, Prausnitz MR. Proc. Natl. Acad. Sci. U.S.A. 2003; 100:13755. [PubMed: 14623977]

209. Liu W, Hu M, Liu W, Xue C, Xu H, Yang X. Int. J. Pharm. 2008; 364:135. [PubMed: 18778760]

210. Lai SK, O'Hanlon DE, Harrold S, Man ST, Wang Y-Y, Cone R, Hanes J. Proc. Natl. Acad. Sci. U.S.A. 2007; 104:1482. [PubMed: 17244708]

211. Papahadjopoulos D, Allen TM, Gabizon A, Mayhew E, Matthay K, Huang S-K, Lee KD, Woodle MC, Lasic DD, Redemann C. Proc. Natl. Acad. Sci. U.S.A. 1991; 88:11460. [PubMed: 1763060]

212. Karmali PP, Simberg D. Expert Opin. Drug Deliv. 2011; 8:343. [PubMed: 21291354]

213. Zhang Y, Zhu C, Pardridge WM. Mol. Ther. 2002; 6:67. [PubMed: 12095305]

214. Doyle WJ, Alper CM, Seroky JT, Karnavas WJ. Acta Otolaryngol. 1998; 118:567. [PubMed: 9726685]

215. Kurabi A, Pak KK, Bernhardt M, Baird A, Ryan AF. Sci. Rep. 2016; 6:22663. [PubMed: 26946957]

216. Du X, Chen K, Kuriyavar S, Kopke RD, Grady BP, Bourne DH, Li W, Dormer KJ. Otol. Neurotol. 2013; 34:41. [PubMed: 23187928]

217. Shapiro B, Dormer K, Rutel IB. AIP conference proceedings. 2010; 1311:77. [PubMed: 21243119]

218. Lai SK, Wang Y-Y, Hanes J. Adv. Drug Deliv. Rev. 2009; 61:158. [PubMed: 19133304]

219. Thornton DJ, Rousseau K, McGuckin MA. Annu. Rev. Physiol. 2008; 70:459. [PubMed: 17850213]

220. Lai SK, Wang Y-Y, Wirtz D, Hanes J. Adv. Drug Deliv. Rev. 2009; 61:86. [PubMed: 19166889]

221. Boegh M, Nielsen HM. Basic Clin. Pharmacol. Toxicol. 2015; 116:179. [PubMed: 25349046]

222. Bansil R, Turner BS. Curr. Opin. Colloid Interface Sci. 2006; 11:164.

223. Larhed AW, Artursson P, Gråsjö J, Björk E. J. Pharm. Sci. 1997; 86:660. [PubMed: 9188047]

224. Norris DA, Sinko PJ. J. Appl. Polym. Sci. 1997; 63:1481.

225. Svensson O, Arnebrant T. Curr. Opin. Colloid Interface Sci. 2010; 15:395.

226. Olmsted SS, Padgett JL, Yudin AI, Whaley KJ, Moench TR, Cone RA. Biophys. J. 2001; 81:1930. [PubMed: 11566767]

227. Amsden B. Macromolecules. 1999; 32:874.

228. Ensign LM, Tang BC, Wang Y-Y, Terence AT, Hoen T, Cone R, Hanes J. Sci. Transl. Med. 2012; 4:138ra79.

229. Henke MO, Ratjen F. Paediatr. Respir. Rev. 2007; 8:24. [PubMed: 17419975]

230. App E, Baran D, Dab I, Malfroot A, Coffiner M, Vanderbist F, King M. Eur. Respir. J. 2002; 19:294. [PubMed: 11866009]

231. Vasconcellos CA, Allen PG, Wohl ME, Drazen JM, Janmey PA, Stossel TP. Science. 1994; 263:969. [PubMed: 8310295]

232. Shak S, Capon DJ, Hellmiss R, Marsters SA, Baker CL. Proc. Natl. Acad. Sci. U.S.A. 1990; 87:9188. [PubMed: 2251263]

233. Duijvestijn Y, Brand P. Acta Paediatr. 1999; 88:38. [PubMed: 10090545]

234. Sanders NN, Franckx H, De Boeck K, Haustraete J, De Smedt SC, Demeester J. Thorax. 2006; 61:962. [PubMed: 17071834]

235. Cobos N, Danes I, Gartner S, Gonzalez M, Linan S, Arnau J, Group DNS. Eur. J. Pediatr. 2000; 159:176. [PubMed: 10664231]

236. Pharmaceuticals, K. 2017. http://kalarx.com/pipeline/pipeline-detail/

237. Caspary WF. The American journal of clinical nutrition. 1992; 55:299S. [PubMed: 1728844]

238. Aoki Y, Morishita M, Asai K, Akikusa B, Hosoda S, Takayama K. Pharm. Res. 2005; 22:1854. [PubMed: 16041494] 
239. Palmeira A, Sousa E, Vasconcelos MH, Pinto MM. Curr. Med. Chem. 2012; 19:1946. [PubMed: 22257057]

240. Kim RB, Fromm MF, Wandel C, Leake B, Wood AJ, Roden DM, Wilkinson GR. J. Clin. Invest. 1998; 101:289. [PubMed: 9435299]

241. Moroz E, Matoori S, Leroux J-C. Adv. Drug Deliv. Rev. 2016; 101:108. [PubMed: 26826437]

242. Maher S, Leonard TW, Jacobsen J, Brayden DJ. Adv. Drug Deliv. Rev. 2009; 61:1427. [PubMed: 19800376]

243. Raoof AA, Chiu P, Ramtoola Z, Cumming IK, Teng C, Weinbach SP, Hardee GE, Levin AA, Geary R. J. Pharm. Sci. 2004; 93:1431. [PubMed: 15124202]

244. Raoof AA, Ramtoola Z, McKenna B, Rosie ZY, Hardee G, Geary RS. Eur. J. Pharm. Sci. 2002; 17:131. [PubMed: 12393140]

245. Chao AC, Nguyen JV, Broughall M, Griffin A, Fix JA, Daddona PE. Int. J. Pharm. 1999; 191:15. [PubMed: 10556736]

246. Roussel, L., Abdayem, R., Gilbert, E., Pirot, F., Haftek, M. Percutaneous Penetration Enhancers Chemical Methods in Penetration Enhancement: Drug Manipulation Strategies and Vehicle Effects. Dragicevic, N., Maibach, HI., editors. Springer Berlin Heidelberg; Berlin, Heidelberg: 2015. p. 69

247. U. S. FDA. Salts of fatty acids, In: Food additives permitted for direct addition to food for human consumption. 2008

248. Tillman LG, Geary RS, Hardee GE. J. Pharm. Sci. 2008; 97:225. [PubMed: 17721945]

249. Ionis Pharmaceuticals Inc. 2016. http://www.prnewswire.com/news-releases/ionispharmaceuticals-licenses-first-oral-antisense-drug-acting-locally-in-the-gi-tract-tojanssen-300300315.html

250. Bittner B, McIntyre C, Tian H, Tang K, Shah N, Phuapradit W, Ahmed H, Chokshi H, Infeld M, Fotaki N. Pharmazie. 2012; 67:233. [PubMed: 22530305]

251. Castelli MC, Wong DF, Friedman K, Riley MGI. Clin. Ther. 2011; 33:934. [PubMed: 21722960]

252. Steinert RE, Poller B, Castelli MC, Drewe J, Beglinger C. Am. J. Clin. Nutr. 2010; 92:810. [PubMed: 20720259]

253. Kidron M, Dinh S, Menachem Y, Abbas R, Variano B, Goldberg M, Arbit E, Bar-On H. Diabetic medicine. 2004; 21:354. [PubMed: 15049938]

254. Maher S, Brayden DJ. Drug Discov. Today Technol. 2012; 9:e113.

255. Alani AWG, Robinson JR. Pharm. Res. 2008; 25:48. [PubMed: 17846867]

256. Schipper NG, Vårum KM, Stenberg P, Ocklind G, Lennernäs H, Artursson P. Eur J Pharm Sci. 1999; 8:335. [PubMed: 10425384]

257. Yin L, Ding J, He C, Cui L, Tang C, Yin C. Biomaterials. 2009; 30:5691. [PubMed: 19615735]

258. Cheng J, Teply BA, Jeong SY, Yim CH, Ho D, Sherifi I, Jon S, Farokhzad OC, Khademhosseini A, Langer RS. Pharm. Res. 2006; 23:557. [PubMed: 16388405]

259. Schoellhammer CM, Schroeder A, Maa R, Lauwers GY, Swiston A, Zervas M, Barman R, DiCiccio AM, Brugge WR, Anderson DG, Blankschtein D, Langer R, Traverso G. J. Acoust. Soc. Am. 2016; 139:2091.

260. Traverso G, Schoellhammer CM, Schroeder A, Maa R, Lauwers GY, Polat BE, Anderson DG, Blankschtein D, Langer R. J. Pharm. Sci. 2015; 104:362. [PubMed: 25250829]

261. Powell JJ, Faria N, Thomas-McKay E, Pele LC. J. Autoimmun. 2010; 34:J226. [PubMed: 20096538]

262. Li H, Zhao X, Ma Y, Zhai G, Li L, Lou H. J. Control. Release. 2009; 133:238. [PubMed: 18951932]

263. Cario E. World J Gastroenterol. 2017; 23:1513. [PubMed: 28321153]

264. Bailey D, Spence J, Munoz C, Arnold J. The Lancet. 1991; 337:268.

265. Choi J-S, Piao Y-J, Kang KW. Arch. Pharm. Res. 2011; 34:607. [PubMed: 21544726]

266. Lerner A, Matthias T. Autoimmun Rev. 2015; 14:479. [PubMed: 25676324]

267. Chassaing B, Koren O, Goodrich JK, Poole AC, Srinivasan S, Ley RE, Gewirtz AT. Nature. 2015; 519:92. [PubMed: 25731162] 
268. Mrázek J, Koppová I, Kopečný J, Šimůnek J, Fliegerová K. Folia Microbiol. 2010; 55:352. [PubMed: 20680570]

269. Banks WA. Nat. Rev. Drug Discov. 2016

270. Saraiva C, Praça C, Ferreira R, Santos T, Ferreira L, Bernardino L. J. Control. Release. 2016; 235:34. [PubMed: 27208862]

271. Oldendorf WH. Proc. Soc. Exp. Biol. Med. 1974; 147:813. [PubMed: 4445171]

272. Aryal M, Arvanitis CD, Alexander PM, McDannold N. Adv. Drug Deliv. Rev. 2014; 72:94. [PubMed: 24462453]

273. Banks WA, Kastin AJ. Brain Res. Bull. 1985; 15:287. [PubMed: 2413968]

274. Chikhale EG, Ng K-Y, Burton PS, Borchardt RT. Pharm. Res. 1994; 11:412. [PubMed: 8008709]

275. Hynynen K, McDannold N, Vykhodtseva N, Jolesz FA. Radiology. 2001; 220:640. [PubMed: 11526261]

276. McDannold N, Arvanitis CD, Vykhodtseva N, Livingstone MS. Cancer Res. 2012; 72:3652. [PubMed: 22552291]

277. Kroll RA, Neuwelt EA. Neurosurgery. 1998; 42:1083. [PubMed: 9588554]

278. Williams PC, Henner WD, Roman-Goldstein S, Dahlborg SA, Brummett RE, Tableman M, Dana BW, Neuwelt EA. Neurosurgery. 1995; 37:17. [PubMed: 8587686]

279. Hervé F, Ghinea N, Scherrmann J-M. AAPS J. 2008; 10:455. [PubMed: 18726697]

280. Schwarze SR, Ho A, Vocero-Akbani A, Dowdy SF. Science. 1999; 285:1569. [PubMed: 10477521]

281. Santana A, Hyslop S, Antunes E, Mariano M, Bakhle Y, De Nucci G. Agents Actions. 1993; 39:104. [PubMed: 8304237]

282. Pardridge WM. Drug Discov. Today. 2007; 12:54. [PubMed: 17198973]

283. Tsuji A, Tamai I. Adv. Drug Deliv. Rev. 1999; 36:277. [PubMed: 10837720]

284. Boado RJ, Li JY, Nagaya M, Zhang C, Pardridge WM. Proc. Natl. Acad. Sci. U.S.A. 1999; 96:12079. [PubMed: 10518579]

285. Wade LA, Katzman R. Am. J. Physiol. 1975; 228:352. [PubMed: 1119556]

286. Georgieva JV, Hoekstra D, Zuhorn IS. Pharmaceutics. 2014; 6:557. [PubMed: 25407801]

287. Atwal JK, Chen Y, Chiu C, Mortensen DL, Meilandt WJ, Liu Y, Heise CE, Hoyte K, Luk W, Lu Y. Sci. Transl. Med. 2011; 3:84ra43.

288. Boado RJ, Hui EKW, Lu JZ, Sumbria RK, Pardridge WM. Bioconjugate Chem. 2013; 24:1741.

289. Boado RJ, Ka-Wai Hui E, Zhiqiang Lu J, Pardridge WM. Biotechnol. Bioeng. 2014; 111:2317. [PubMed: 24889100]

290. Pardridge WM. Expert Opin. Drug Deliv. 2015; 12:207. [PubMed: 25138991]

291. Schinkel AH. Adv. Drug Deliv. Rev. 1999; 36:179. [PubMed: 10837715]

292. Somjen G, Segal M, Herreras O. Exp. Physiol. 1991; 76:507. [PubMed: 1910758]

293. Jambroszyk M, Tipold A, Potschka H. Epilepsia. 2011; 52:284. [PubMed: 21219313]

294. Nicita F, Spalice A, Papetti L, Nikanorova M, Iannetti P, Parisi P. Seizure. 2014; 23:36. [PubMed: 24113539]

295. Dogrukol-Ak D, Kumar VB, Ryerse JS, Farr SA, Verma S, Nonaka N, Nakamachi T, Ohtaki H, Niehoff ML, Edwards JC, Shioda S, Morley JE, Banks WA. J. Cereb. Blood Flow Metab. 2009; 29:411. [PubMed: 19002200]

296. Sugarman JL, Fluhr JW, Fowler AJ, Bruckner T, Diepgen TL, Williams ML. Arch. Dermatol. 2003; 139:1417. [PubMed: 14623701]

297. van Sorge NM, Doran KS. Future Microbiol. 2012; 7:383. [PubMed: 22393891]

298. Nau R, Sörgel F, Eiffert H. Clin. Microbiol. Rev. 2010; 23:858. [PubMed: 20930076]

299. Adelson, PD., Whalen, MJ., Kochanek, PM., Robichaud, P., Carlos, TM. Intracranial Pressure and Neuromonitoring in Brain Injury: Proceedings of the Tenth International ICP Symposium, Williamsburg, Virginia, May 25-29, 1997. Marmarou, A.Bullock, R.Avezaat, C.Baethmann, A.Becker, D.Brock, M.Hoff, J.Nagai, H.Reulen, H-J., Teasdale, G., editors. Springer Vienna; Vienna: 1998. p. 104 
300. Price TO, Eranki V, Banks WA, Ercal N, Shah GN. Endocrinology. 2011; 153:362. [PubMed: 22109883]

301. Hammes H-P, Lin J, Renner O, Shani M, Lundqvist A, Betsholtz C, Brownlee M, Deutsch U. Diabetes. 2002; 51:3107. [PubMed: 12351455]

302. Armulik A, Genove G, Mae M, Nisancioglu MH, Wallgard E, Niaudet C, He L, Norlin J, Lindblom P, Strittmatter K, Johansson BR, Betsholtz C. Nature. 2010; 468:557. [PubMed: 20944627]

303. Hackel D, Krug SM, Sauer R-S, Mousa SA, Böcker A, Pflücke D, Wrede E-J, Kistner K, Hoffmann T, Niedermirtl B. Proc. Natl. Acad. Sci. U.S.A. 2012; 109:E2018. [PubMed: 22733753]

304. Tallarida RJ. Genes Cancer. 2011; 2:1003. [PubMed: 22737266]

305. Römgens AM, Bader DL, Bouwstra JA, Baaijens FP, Oomens CW. J. Mech Behav. Biomed. Mater. 2015; 50:215. [PubMed: 26151288]

306. Han T, Das DB. Eur. J. Pharm. Biopharm. 2015; 89:312. [PubMed: 25541440]

307. Timko BP, Dvir T, Kohane DS. Adv. Mater. 2010; 22:4925. [PubMed: 20818618]

308. Rwei AY, Wang W, Kohane DS. Nano Today. 2015; 10:451. [PubMed: 26644797]

309. Wang Y, Kohane DS. Nat. Rev. Mater. 2017; 2:17020.

310. Chen M-C, Ling M-H, Wang K-W, Lin Z-W, Lai B-H, Chen D-H. Biomacromolecules. 2015; 16:1598. [PubMed: 25839774]

311. Indulekha S, Arunkumar P, Bahadur D, Srivastava R. Mater. Sci. Eng. C Mater. Biol. Appl. 2016; 62:113. [PubMed: 26952404]

312. Pitt WG, Husseini GA, Staples BJ. Expert Opin. Drug Deliv. 2004; 1:37. [PubMed: 16296719]

313. Murthy SN, Sen A, Hui SW. J. Control. Release. 2004; 98:307. [PubMed: 15262421]

314. Hoopes MI, Noro MG, Longo ML, Faller R. J. Phys. Chem. B. 2011; 115:3164. [PubMed: 21370846]

\section{Biographies}

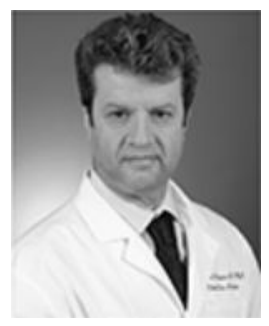

Prof. Daniel S. Kohane M.D., Ph.D.'s research covers broad areas in biomaterials, drug delivery, and nanoscience. He has particular interests in the effects of chemical permeation enhancers in peripheral nerve and in the ear, and in triggered and targeted drug delivery systems responsive to a range of external energy sources. He directs the Laboratory for Biomaterials and Drug Delivery at Boston Children's Hospital at Harvard Medical School. His clinical expertise is in pediatrics, anesthesiology, and pediatric critical care medicine. 


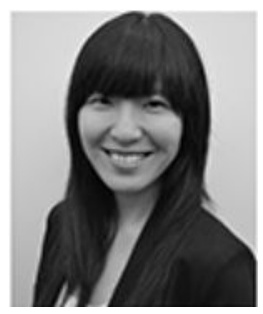

Dr. Rong Yang obtained her Ph.D. in Chemical Engineering from MIT in 2014, developing vapor-printed functional polymer thin films for sustainability. From 2014 to 2016, she conducted her postdoctoral research with Professors Daniel S. Kohane and Robert Langer, in the treatment of infectious diseases using multicomponent hydrogel systems. She joined the faculty at Harvard Medical School in 2016. Her work is focused on the trans-tympanic drug delivery and mitigation of antibiotic resistance. 


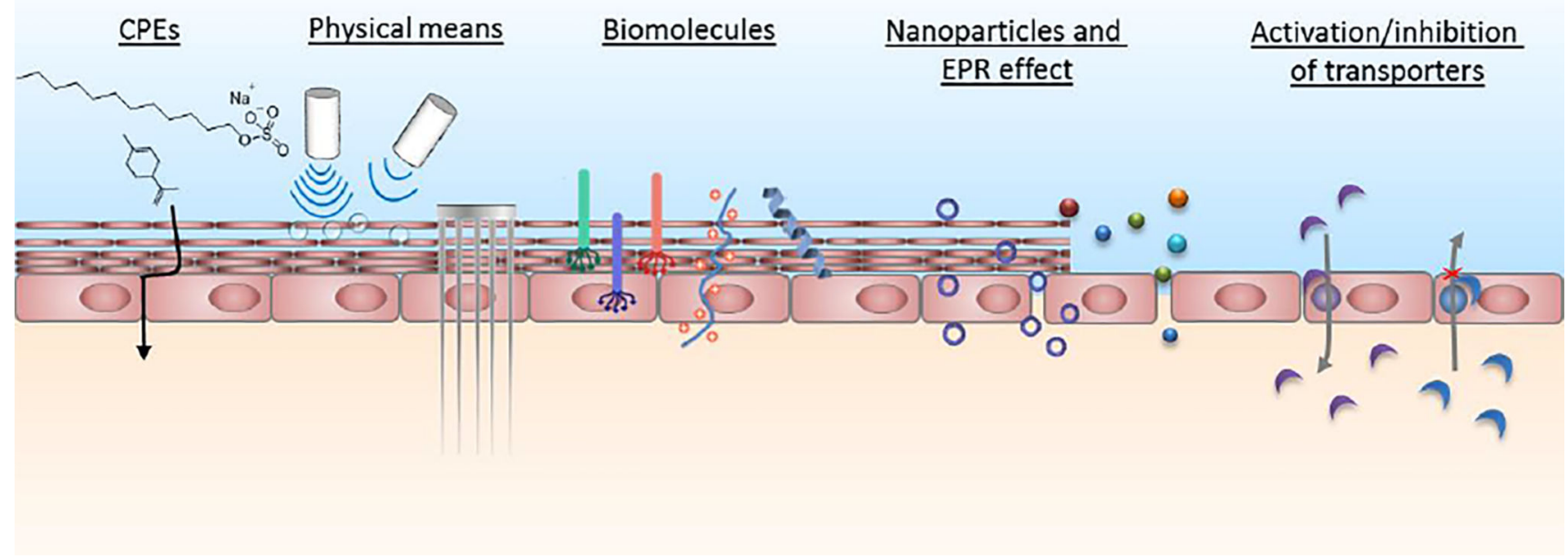

Figure 1.

Summary of strategies to overcome biological barriers. CPEs: chemical permeation enhancers. 


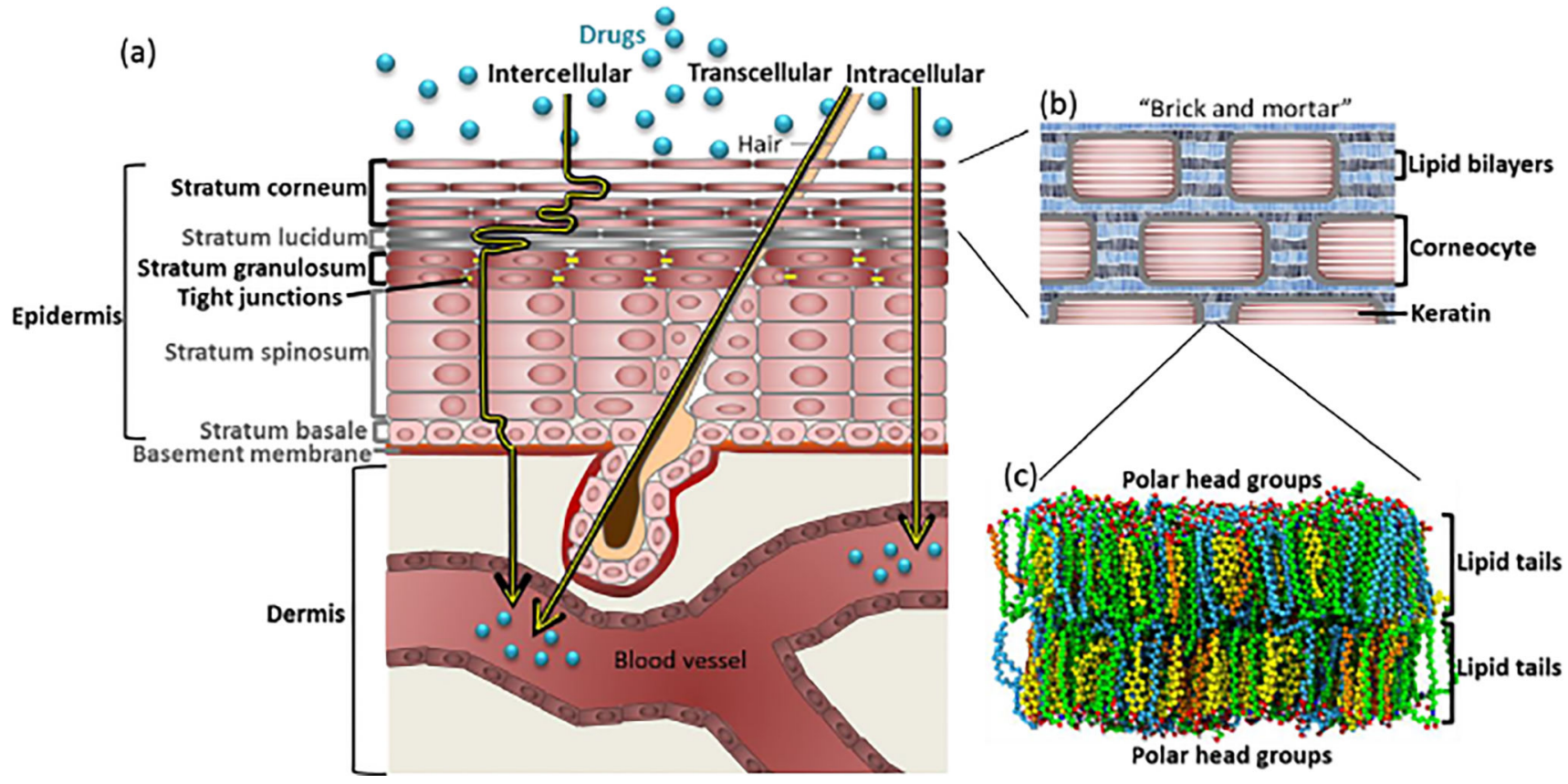

Figure 2.

Drug transport across skin. (a) The stratum corneum (SC) is the outermost layer of skin and the major barrier to transport. Molecules can permeate via the intercellular, transcellular, and intracellular routes. The cell layers discussed in the text are in black. (b) Permeation across the SC is primarily limited by lipids (mortar), which fill the spaces between corneocytes (bricks). (c) Lipids filling the spaces between corneocytes are arranged in a bilayer structure, with hydrophobic tails on the inside and polar head groups on the outside. Lipids are mainly cholesterol (yellow), free fatty acids (blue), and ceramides (green). (c) is adapted with permission from ${ }^{[314]}$. Copyright 2011 American Chemical Society. 


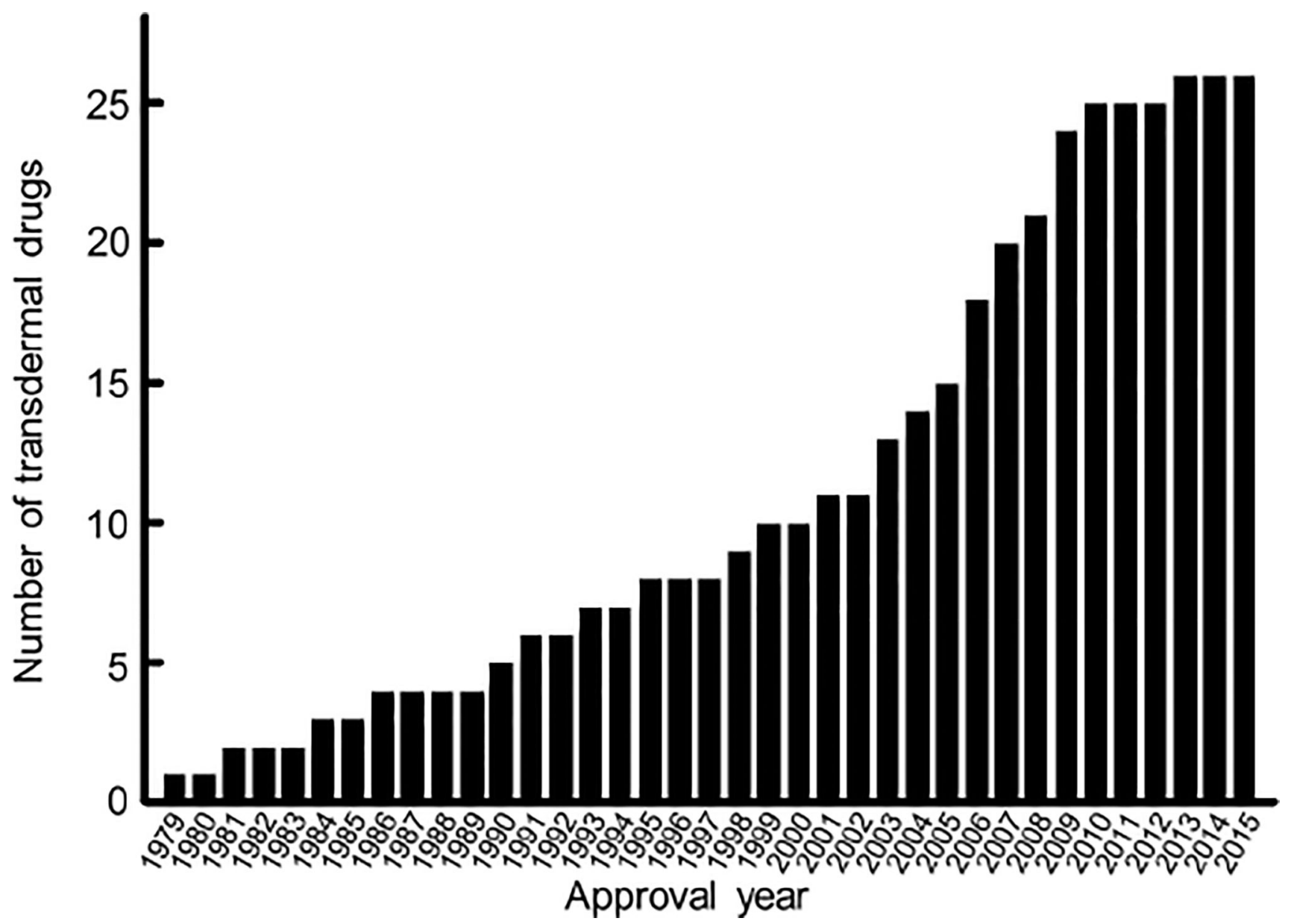

Figure 3.

Total number of US FDA-approved transdermal drug formulations over time. Data were obtained from the FDA Orange Book. ${ }^{[34]}$ 
A
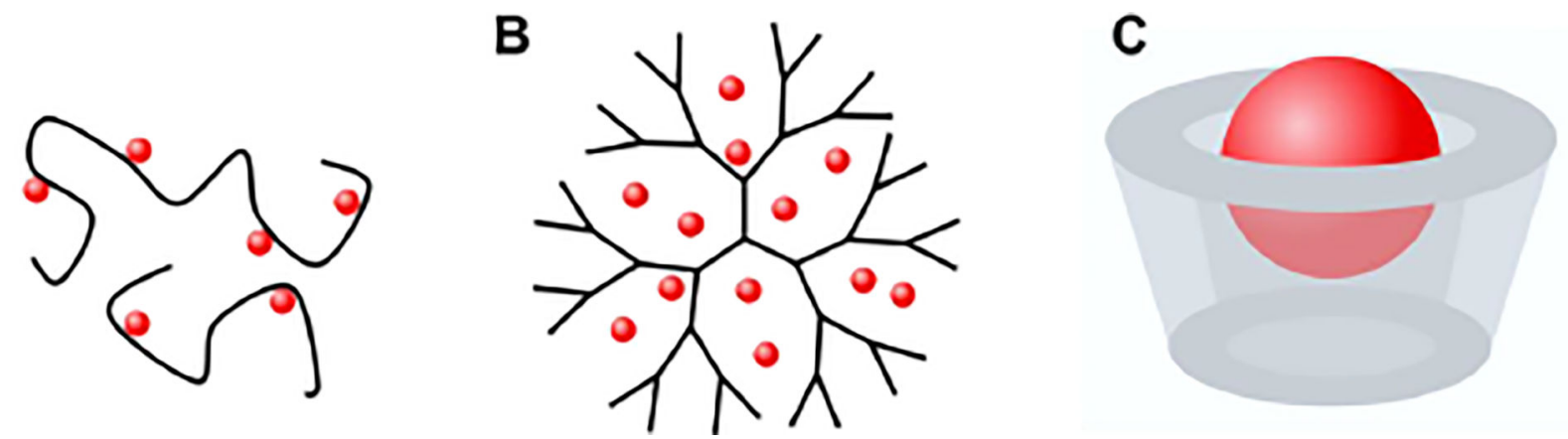

Figure 4.

Drug loading of macromolecule-based chemical permeation enhancers. (A) hyaluronic aciddrug conjugate; (B) drug-encapsulating dendrimer; (C) cyclodextrin-drug complex. The red spheres represent the drugs. 


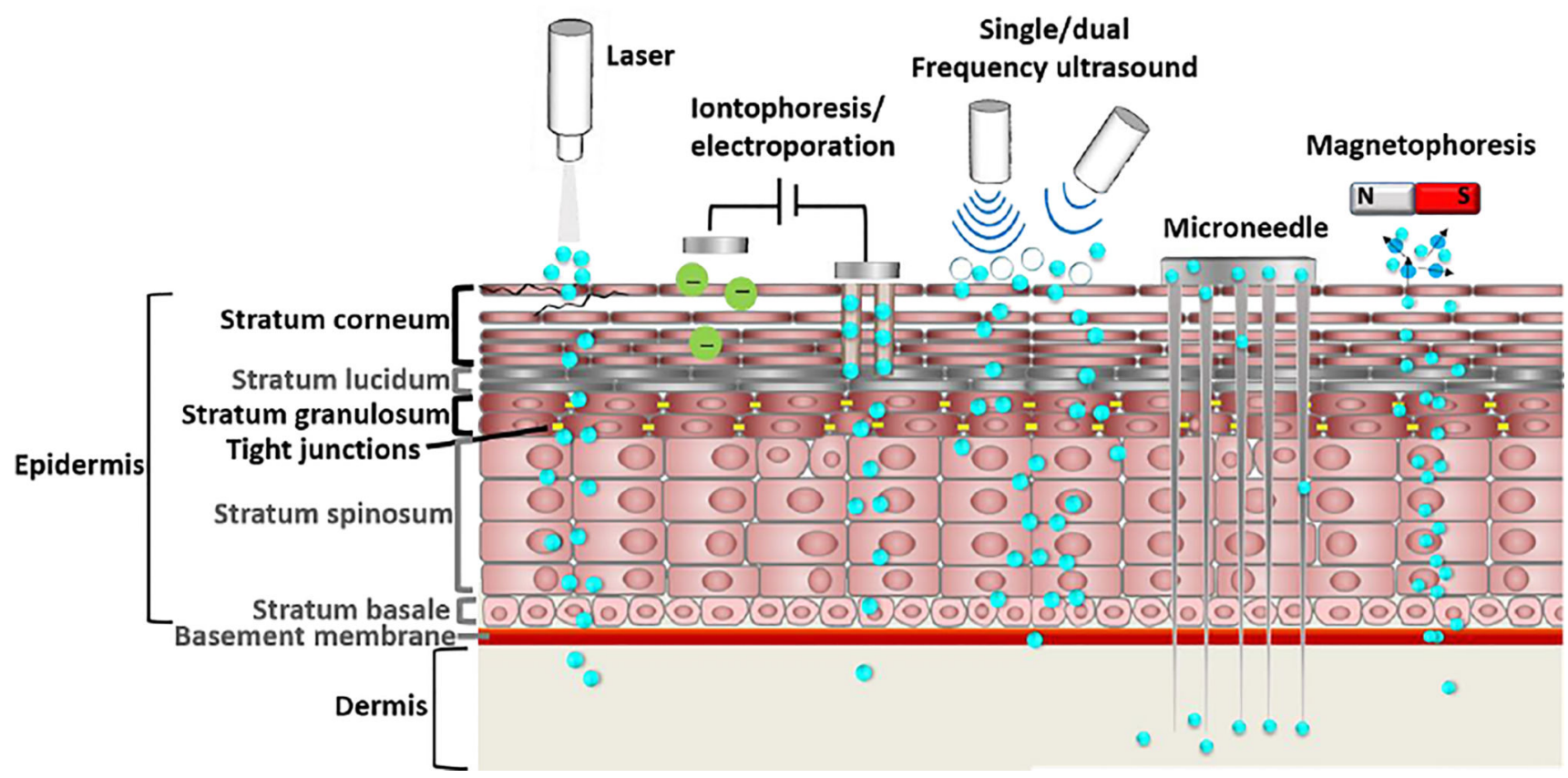

Figure 5.

Physical mechanisms to enhance transdermal drug delivery. Blue dots represent therapeutics; white circies under single/dual frequency ultrasound represent microbubbles. 


\section{Cell-penetrating peptides}

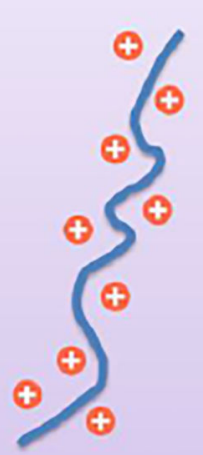

positive
R7-9: RRRRRRRRR

TAT: YGRKKRRQRRR

YKA: YKALRISRKLAK

YARA: YARAAARQARA

RALA:

RALARALARALRALAR

Penetratin:

RQIKIWFQNRRMKWKK

\section{Antimicrobial peptides}

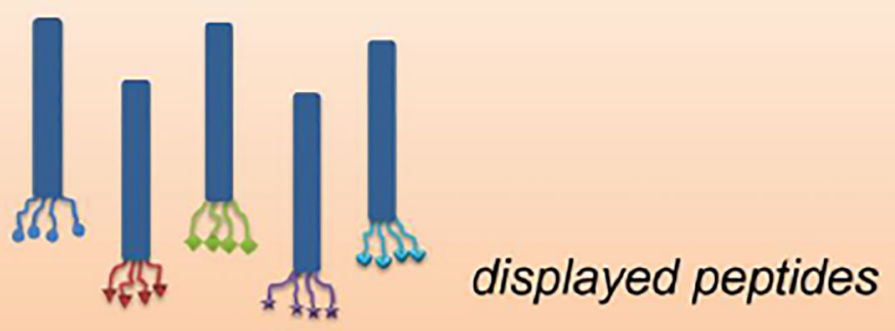

Magainin: GIGKFLHSAKKFGKAFV GEIMNS

Phage peptides

TD-1: ACSSSPSKHCG SPACE: ACTGSTQHQCG
T2: LVGVFH

DRTTLTN

Figure 6.

Selected peptide sequences of the three categories of skin penetrating peptides: cellpenetrating peptides, antimicrobial peptides, and phage peptides. 


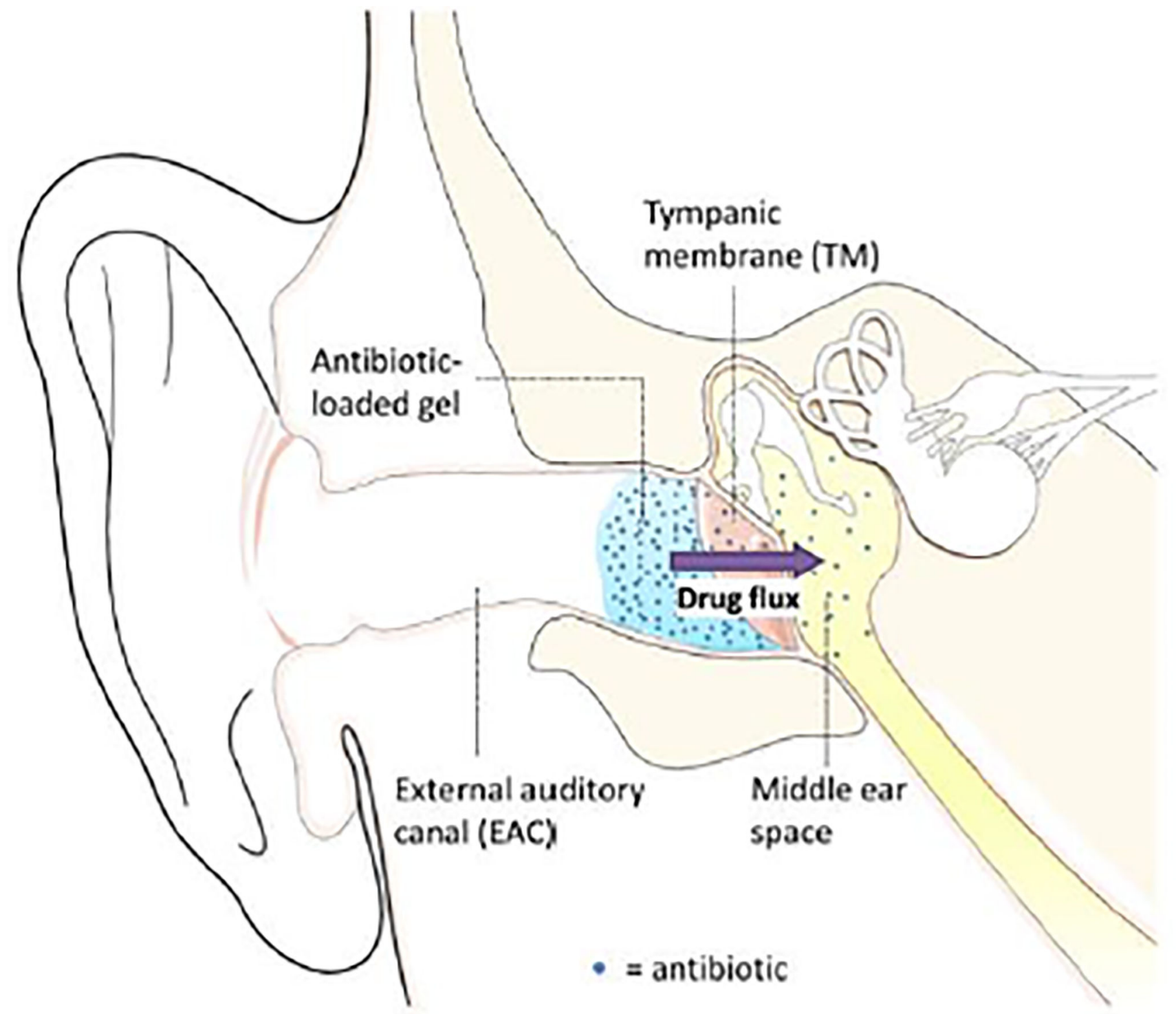

Figure 7.

Schematic representation of an in-situ forming antibiotic-loaded hydrogel at the tympanic membrane (TM). Antibiotics diffuse out of the gel, across the TM (with the assistance of CPEs), and into the infected middle ear. From [9]. Permission obtained from Elsevier. 
Table 1

Excipients with permeation-enhancing activity approved by the US FDA. ${ }^{[46]}$

\begin{tabular}{llr}
\hline Name & $\begin{array}{l}\text { Chemical abstract } \\
\text { service (CAS) number }\end{array}$ & $\begin{array}{r}\text { FDA-approved } \\
\text { concentration upper limit }\end{array}$ \\
\hline Decyl methyl sulfoxide & 3079285 & $0.13 \mathrm{w} / \mathrm{v} \%$ \\
Diethyl sebacate & 110407 & $24 \mathrm{w} / \mathrm{v} \%$ \\
Dimethyl sulfoxide & 67685 & $45.5 \mathrm{w} / \mathrm{w} \%$ \\
Limonene, (+/-) & 138863 & $10 \mathrm{w} / \mathrm{v} \%$ \\
Isopropyl palmitate & 142916 & $7.3 \mathrm{w} / \mathrm{v} \%$ \\
Isopropyl myristate & 110270 & $31.35 \mathrm{w} / \mathrm{w} \%$ \\
Methyl Laurate & 111820 & $0.25 \mathrm{w} / \mathrm{w} \%$ \\
Nonoxynol-9 & 26027383 & $0.01 \mathrm{w} / \mathrm{v} \%$ \\
Octoxynol-9 & 9002931 & $0.12 \mathrm{w} / \mathrm{w} \%$ \\
Octyldodecanol & 5333426 & $13.5 \mathrm{w} / \mathrm{v} \%$ \\
Oleic acid & 112801 & $25 \mathrm{w} / \mathrm{v} \%$ \\
Polysorbate 20 & 9005645 & $15 \mathrm{w} / \mathrm{w} \%$ \\
Polysorbate 40 & 9005667 & $3 \mathrm{w} / \mathrm{w} \%$ \\
Sodium lauryl sulfate & 151213 & $40 \mathrm{w} / \mathrm{v} \%$ \\
Sodium lauroyl sarcosinate & 137166 & $0.75 \mathrm{w} / \mathrm{v} \%$ \\
Sodium polyacrylate (2500000 MW) & 9003047 & $\mathrm{NA}$ \\
Sodium pyrrolidone carboxylate & 54571674 & $5.2 \mathrm{w} / \mathrm{v} \%$ \\
Sorbitan Monooleate & 1338438 & $7 \mathrm{w} / \mathrm{w} \%$ \\
\hline & &
\end{tabular}


Table 2

Chemical permeation enhancers and their molecular structures. ${ }^{*}$

\begin{tabular}{|c|c|c|c|c|}
\hline Name & Molecular structure & $\begin{array}{l}\text { Molecular } \\
\text { weight } \\
\text { [Da] }\end{array}$ & Class & $\log P$ \\
\hline Pyrrolidone & & 85.1 & Solvent & -0.9 \\
\hline Sodium pyrrolidone carboxylate & & 151.1 & Solvent & n.a. \\
\hline Dimethyl sulfoxide & & 78.1 & Solvent & -1.4 \\
\hline Decyl methyl sulfoxide & & 204.4 & Solvent & 3.8 \\
\hline Oleic acid & & 282.5 & Fatty acid & 7.7 \\
\hline Sodium lauryl sulfate & & 288.4 & Anionic surfactant & 1.6 \\
\hline Sodium octyl sulfate & & 232.3 & Anionic surfactant & n.a. \\
\hline Sodium laureth sulfate & & 332.4 & Anionic surfactant & n.a. \\
\hline Nonoxynol-9 & & 616.8 & Non-ionic surfactant & 3.4 \\
\hline Limonene (terpene) & & 136.2 & Terpene & 4.6 \\
\hline
\end{tabular}


* Data were obtained from the PubChem Open Chemistry Database by the National Center for Biotechnology Information (http:// www.ncbi.nlm.nih.gov/pccompound). 
Table 3

Physical enhancement methods approved by the US FDA

\begin{tabular}{|c|c|c|c|}
\hline Mechanism & Product name & Marketing company & $\begin{array}{l}\text { Year of initial } \\
\text { commercialization }\end{array}$ \\
\hline \multirow[t]{2}{*}{ Microneedle } & Macroflux $^{\circledR}$ & Zosano Pharma & 2002 \\
\hline & Micronjet ${ }^{\circledR}$ & NanoPass Techonolgies & 2009 \\
\hline Ultrasound & SonoPrep ${ }^{\circledR}$ & Sontra Medical & 2004 \\
\hline \multirow[t]{7}{*}{ Iontophoresis } & Iontocaine $^{\circledR}$ & Iomed & 1995 \\
\hline & Phoresor $^{\circledR}$, LidoSite $^{\mathrm{TM}}$ & Chattanooga Group & 2000 \\
\hline & E-trans ${ }^{\circledR}$ & Vyteris & 2004 \\
\hline & Zecuity ${ }^{\circledR}$ & Alza Coorporation & 2004 \\
\hline & Ionsys ${ }^{\circledR}$ & NuPathe Inc. & 2015 \\
\hline & Hybresis $^{\circledR}$ & Alza Coorporation & 2006 \\
\hline & & Iomed/EMPI & 2007 \\
\hline \multirow[t]{2}{*}{ Electroporation } & Cellectra $^{\circledR}$ & Ionvio & 2013 \\
\hline & ViaDerm $^{\circledR}$ & & \\
\hline Laser & P.L.E.A.S.E ${ }^{\circledR}$ & Pantec Biosolutions & 2008 \\
\hline
\end{tabular}

